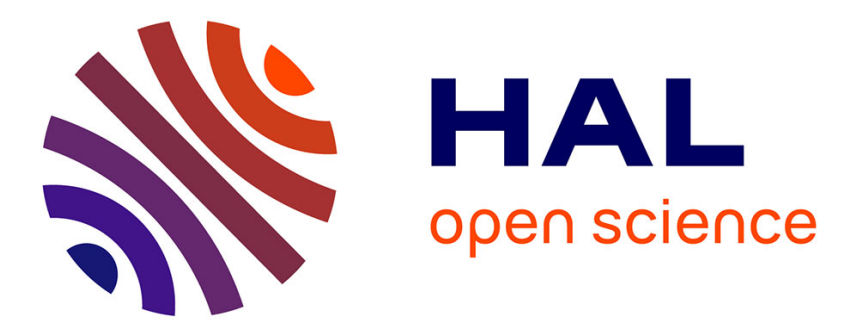

\title{
Segmental Dynamics of Poly(ethylene oxide) Chains in a Model Polymer/Clay Intercalated Phase: Solid-State NMR Investigation
}

Cédric Lorthioir, Françoise Lauprêtre, Jérémie Soulestin, Jean Marc Lefebvre

\section{- To cite this version:}

Cédric Lorthioir, Françoise Lauprêtre, Jérémie Soulestin, Jean Marc Lefebvre. Segmental Dynamics of Poly(ethylene oxide) Chains in a Model Polymer/Clay Intercalated Phase: Solid-State NMR Investigation. Macromolecules, 2009, 42 (1), pp.218-230. 10.1021/ma801909s . hal-03183442

\author{
HAL Id: hal-03183442 \\ https://hal.science/hal-03183442
}

Submitted on 29 Mar 2021

HAL is a multi-disciplinary open access archive for the deposit and dissemination of scientific research documents, whether they are published or not. The documents may come from teaching and research institutions in France or abroad, or from public or private research centers.
L'archive ouverte pluridisciplinaire HAL, est destinée au dépôt et à la diffusion de documents scientifiques de niveau recherche, publiés ou non, émanant des établissements d'enseignement et de recherche français ou étrangers, des laboratoires publics ou privés. 


\section{Segmental Dynamics of Poly(ethylene oxide) Chains}

\section{in a Model Polymer/Clay Intercalated Phase:}

\section{Solid-State NMR Investigation}

Cédric Lorthioir, ${ }^{*}+\dagger$ Françoise Lauprêtre, ${ }^{\dagger}$ Jérémie Soulestin, ${ }^{+}$Jean-Marc Lefebvre.

(†) Equipe "Systèmes Polymères Complexes",

Institut de Chimie et des Matériaux Paris-Est (UMR 7182 CNRS / Université Paris XII),

2-8 rue Henri Dunant, 94320 Thiais, France

(†) Laboratoire de Structure et Propriétés de l’Etat Solide (UMR 8008 CNRS / Université Lille I),

Université des Sciences et Technologie de Lille,

Bâtiment C6, 59655 Villeneuve d'Ascq Cedex, France 
AUTHOR EMAIL ADDRESS.

lorthioir@icmpe.cnrs.fr (C. Lorthioir)

laupretre@icmpe.cnrs.fr (F. Lauprêtre)

soulestin@ensm-douai.fr (J. Soulestin)

Jean-Marc.Lefebvre@univ-lille1.fr (J.-M. Lefebvre)

RECEIVED DATE (to be automatically inserted after your manuscript is accepted if required according to the journal that you are submitting your paper to)

TITLE RUNNING HEAD.

Segmental Dynamics in a Model Intercalated Phase.

CORRESPONDING AUTHOR FOOTNOTE.

C. Lorthioir, Tel.: +3314978 13 08, Fax: +33 1497812 08, E-mail: lorthioir@icmpe.cnrs.fr 


\section{ABSTRACT}

A model poly(ethylene oxide) (PEO)/laponite hybrid material, characterized by a high silicate content, was used to probe the dynamical behaviour of polymer chains at the surface with clay platelets. Such a system mimics the intercalated phases that may occur in polymer/clay nanocomposites with usual silicate amounts of $5 \mathrm{wt} \%$. The segmental motions underlying the $\alpha$-relaxation of fully amorphous PEO chains confined within the nanometer-thick laponite galleries were monitored over the tens of microseconds time scale by means of ${ }^{13} \mathrm{C}$ and ${ }^{1} \mathrm{H}$ solid-state NMR. A significant slowing down of these motions was mostly observed, as compared to the local dynamics in the amorphous phase of neat PEO. Strong dynamical heterogeneities among the intercalated PEO monomer units remain even at room temperature, i.e. more than $50 \mathrm{~K}$ above the temperature at which the frequency of the segmental motions displayed by a significant part of the PEO chain segments gets above $52 \mathrm{kHz}$. Such heterogeneities are related to a pronounced extension of the $\alpha$-relaxation process towards the low frequency side. The slowing down of the PEO segmental motions was assigned to ion-dipole interactions between the PEO oxygen atoms and the $\mathrm{Na}^{+}$counterions located in the laponite galleries. The domains formed by PEO monomer units characterized by a reduced segmental mobility were found to display rather long lifetime, about $13 \mathrm{~ms}$ at room temperature. 


\section{MANUSCRIPT TEXT}

\section{Introduction.}

Polymer-based nanocomposites are of great current interest since the incorporation of inorganic nanosized fillers may, in some cases, lead to a strong enhancement of several macroscopic properties of the pristine polymer matrix. ${ }^{1,2}$ Polymer/clay structures are one of the most widely studied classes of organic/inorganic nanocomposites. Significant improvements of the mechanical, thermal and barrier properties of such materials with respect to the neat polymer matrix on the one hand and microcomposites prepared with the same matrix on the other hand have been reported in the literature..$^{3,4}$ As far as the mechanical behaviour is concerned, one of the key parameter that must be optimized is the contact area between the polymer matrix and the filler particles. This experimental trend suggests that the behaviour of polymer chains at the interface with the clay platelets plays an important role in the mechanical performances displayed by polymer/clay nanocomposites.

Several theoretical and simulations-based approaches were developed in order to get a fine description of the influence of the clay platelets on both conformational and dynamical properties of the surrounding polymer chains. ${ }^{5-10}$ The comparison of these works with experimental results are of a great interest and promising investigations were carried out along this line. ${ }^{6-8}$ However, from an experimental point of view, several difficulties make the study of the interfacial phenomena in polymer/clay nanocomposites a rather challenging problem.

First, various morphologies may be obtained by blending polymer chains with clay platelets, depending on the preparation conditions and the nature of both blend components. The bulk polymer/clay materials may contain tactoids dispersed in the polymer matrix, intercalated phases, exfoliated phases or, more usually, a mixture of these different morphological structures. ${ }^{11}$ The effect of the clay layers on the static and dynamic behaviour of the surrounding polymer chains depends on the local polymer/clay organization. Indeed, the polymer chain radius of gyration $R_{\mathrm{g}}$ is limited by the thickness of the clay interlayer galleries in the case of intercalated phases, i.e. about $1.0 \mathrm{~nm}$, while for 
exfoliated phases, $R_{\mathrm{g}}$ is limited by the average interlayer distance, which may amount to at least a few tens of nanometers. Of course, the value of this distance depends on the clay content in the nanocomposite. As a result, a less severe geometrical chain confinement should be involved in the exfoliated phases and a lower local constraint on the polymer chains is expected. This difference is one of several features that should make the chain behaviour at the interfaces with the clay layers distinct between intercalated and exfoliated phases. Therefore, a fine description of the polymer chains in the vicinity of the clay platelets should ideally be carried out on isolated structural morphologies. These ones cannot be always easily obtained. One way to circumvent this first difficulty is to use a high clay content, which may lead, in some cases, to neat intercalated phases. ${ }^{12-14}$ The preparation of pure exfoliated phases is more complex and several strategies have been recently developed for this purpose. $^{15,16}$

The second difficulty is related to the experimental approaches available to probe interfacial phenomena, from a dynamical point of view. Broadband dielectric relaxation spectroscopy has proved to be a very efficient approach to investigate the dynamics in heterogeneous polymer systems, covering a wide frequency range. In particular, this relaxation technique was used to probe the segmental dynamics as well as the fluctuations of the end-to-end vector for polymers with molecular dipole vectors oriented parallel to the main chain, in polymer/clay nanocomposites. ${ }^{13,14,17-19}$ The effect of the clay platelets on the segmental and normal mode of the polymer chains was considered. These studies were mostly carried out on polymer matrices filled with rather modest clay contents, typically lower than 5$10 \mathrm{wt} \%$, since this is the typical value required to get a significant enhancement of their macroscopic properties. ${ }^{17,18}$ However, the nanocomposite materials considered in these studies usually consisted in a mixture of different polymer/clay morphologies. In addition, in some cases, the conductivity contribution to the dielectric permittivity increases with the clay content and an additional Maxwell/Wigner/Sillars process occurs. ${ }^{17,18}$ Both contributions may superimpose with the relaxation processes related to polymer chains and the data analysis is not straightforward. For these reasons, nanocomposites characterized by a high clay content are not necessarily well-suited to probe the chain dynamics using dielectric relaxation spectroscopy measurements, even though such a strategy may 
allow to get a pure morphological phase (intercalated phase). At this stage, it should be noted that this is not the case for all the clays. Indeed, Schwartz et al. took advantage of broadband dielectric relaxation spectroscopy to investigate both segmental and end-to-end vector dynamics of poly(propylene glycol) (PPG) chains within samples characterized by high vermiculite clay contents, high enough to get a neat intercalated phase. ${ }^{14}$ In this work, the contribution of both conductivity and interfacial polarization process was limited and both PPG segmental and normal relaxation peaks could be directly observed and characterized on the basis of isothermal measurements of the dielectric loss $\varepsilon$ "' $(\omega)$. No significant change in the $\alpha$-relaxation process was detected, in contrast to the normal mode. Similarly, Anastasiadis et al. considered poly(methylphenylsiloxane) (PMPS) oligomers intercalated in the galleries of two different organically-modified clays, montmorillonite and hectorite. ${ }^{13}$ Again, high values of the clay weight fraction, above $70 \mathrm{wt} \%$, were used. In contrast with the results observed on PPG, the PMPS $\alpha$ relaxation process measured under isothermal conditions displays a strong shift towards high frequencies, as compared to the one observed on neat PMPS.

Solid-state nuclear magnetic resonance (NMR) spectroscopy is a powerful technique that has been successfully used in the last few years to describe various structural and dynamical features of polymer/clay nanocomposites, at the molecular length scale. Most of the polymer/clay nanocomposites described in the literature are based on naturally occurring layered silicates, which may contain paramagnetic species in more or less important quantities. In montmorillonite platelets for instance, the octahedral sites may be occupied by paramagnetic $\mathrm{Fe}^{3+}$ ions, instead of $\mathrm{Al}^{3+}$. VanderHart et al. took advantage of the paramagnetic contribution to the ${ }^{1} \mathrm{H}$ relaxation properties in order to characterize the dispersion of the clay platelets in polystyrene or nylon- 6 matrices and to investigate the nature of the nylon-6 crystallites ( $\alpha$-phase and/or $\gamma$-phase) close to the silicate layers. ${ }^{20-22}$ However, most NMR studies were dedicated to synthetic clays or naturally occurring clays with a low content of paramagnetic species. The conformational behaviour of poly(ethylene oxide) (PEO) chains in intercalated phases was probed by $1 \mathrm{D}{ }^{13} \mathrm{C}$ NMR experiments ${ }^{23}$ and, more recently, a more precise description was obtained by means of $2 \mathrm{D}$ double-quantum experiments carried out on ${ }^{13} \mathrm{C}-{ }^{13} \mathrm{C}$ labelled 
PEO monomer units. ${ }^{24}$ Solid-state NMR also served the study of the different dynamical processes involved in these nanocomposites. ${ }^{7} \mathrm{Li}$ and ${ }^{23} \mathrm{Na} \mathrm{NMR}$ line shape analysis and spin-lattice relaxation time $\left(T_{1}\right)$ measurements were performed to monitor the dynamics of the counterions located in the clay interlayer galleries. ${ }^{25-28}$ From another point of view, the molecular motions of polymer chains were probed within nanocomposites based on PEO chains which display strong attractive interactions with the silicate layer surfaces. ${ }^{25,26,29-31}$ The case of polymers that do not display any propensity to intercalate the clay interlayer galleries, such as polystyrene (PS), was also considered. ${ }^{12,31}$ This is a more complex situation from a dynamical point of view, since a third component, quaternary ammonium salt surfactants usually, has to be introduced to enable the polymer chain intercalation. At this stage, it is worth noting that most of the NMR studies dedicated to the polymer chain dynamics within clay-based nanocomposites involved NMR experiments sensitive to the molecular motions occurring on the microsecond time scale. Investigation of the chain dynamics on the millisecond time scale was carried out recently on $\mathrm{PEO}$ and PS-based nanocomposites using two-dimensional ${ }^{2} \mathrm{H}$ exchange NMR experiments. ${ }^{31}$ Moreover, the segmental dynamics in the shorter time scale range of $10^{-11}-10^{-7} \mathrm{~s}$ was recently addressed in the case of PEO/synthetic fluoromica intercalated phases by means of electron spin resonance. ${ }^{32}$ For this purpose, nitroxide labels located at one of the PEO chain ends were introduced.

The references to NMR investigations mentioned previously concern polymer/clay nanocomposites with high clay contents. Interestingly, Schmidt-Rohr et al. proposed powerful $2 \mathrm{D}{ }^{29} \mathrm{Si}-$ ${ }^{1} \mathrm{H},{ }^{1} \mathrm{H}-{ }^{1} \mathrm{H}$ and ${ }^{1} \mathrm{H}-{ }^{13} \mathrm{C}$ NMR approaches to extend the study of the chain dynamics at the interface with the clay layers, to nanocomposites composed of lower amounts of clay platelets. ${ }^{30}$ These experiments enable to describe the nature and the mobility of the species located in the vicinity of the inorganic layers. Such 2D NMR methods were successfully applied to nanocomposites with rather complex polymer matrices such as block copolymers ${ }^{33}$ or miscible polymer blends. ${ }^{34}$

Investigations of the polymer chain dynamics within clay galleries should serve to a better understanding and modelling of the mechanical properties displayed by polymer/clay nanocomposites as well as the dynamics in ultrathin polymer films. Indeed, the intercalated phases offer a 2D 
confinement geometry where the polymer chains form (ultra)thin films, characterized by a rather welldefined confining length of about $1 \mathrm{~nm}$. This characteristic length is much smaller than the ones that can be achieved using usual confining matrices ${ }^{35}$ and should amplify the confinement effects on the chain dynamics. In this respect, one may expect the geometric confinement imposed by the clay layers on the polymer chains to result in segmental motions faster than in the bulk matrix, as reported in previous investigations of PEO/clay intercalated phases for instance. ${ }^{19,26,29,31,32}$ In the case of PEO, several features were proposed to account for this confinement effect on the segmental dynamics. First, the local density was found to be lower for PEO chains confined by phyllosilicate platelets than for amorphous PEO in the bulk state. ${ }^{32}$ Second, as the temperature tends to the glass transition temperature of bulk PEO, the PEO segmental motions in a confined space should mainly involve rather localized, weakly cooperative motions. ${ }^{19,32}$ This limitation may lead to a correlation time value shorter than the characteristic correlation time related to the $\alpha$-relaxation of bulk PEO, at the same temperature. Lastly, the possible decrease of the chain entanglement density in a 1D-confined space by comparison with the bulk case could also explain the enhanced segmental dynamics. ${ }^{32}$

Besides, the dynamical behaviour of polymer chains in thin films and the characterization of its heterogeneity are yet open topics. The question of the glass transition phenomenon in thin polymer films was recently addressed, from a theoretical point of view, through several different models, which were mostly dedicated to Van der Waals liquids. ${ }^{36,37}$ However, to our knowledge, these approaches were not yet extended to the case of polymers involved in other kinds of interactions, such as hydrogen bonds for instance. Experimental data in this field may fruitfully serve the development of such theoretical models.

With these features in mind, we have considered polymer/clay nanocomposites, poly(ethylene oxide) (PEO)/laponite namely, characterized by high clay contents (50-70 wt \%). Poly(ethylene oxide) displays attractive interactions with the large faces of the clay platelets and does not require the use of surfactants, such as quaternary ammonium salt surfactants, to intercalate the silicate galleries. Such lowmolecular-weight molecules may indeed affect the segmental motions of the polymer chains and make the analysis of the dynamical behaviour more complex. Laponite was chosen as the clay component for 
two reasons. First, this phyllosilicate consists in platelets displaying a discoid shape, with well-defined dimensions: the clay layer thickness is of about $0.92 \mathrm{~nm}$ while its diameter amounts to $25 \mathrm{~nm}$. These dimensions display a rather limited distribution and the disc diameter is at least less polydisperse than the lateral size of natural clay layers. Moreover, naturally occurring clays may contain paramagnetic species, such as $\mathrm{Fe}^{3+}$ ions in the case of montmorillonite, the concentration of which depends on their nature and their origin. Even though the effect of such paramagnetic species on the relaxation behaviour of the surrounding protons may be fruitfully used to probe the clay platelet dispersion within the polymer matrix, ${ }^{20-22}$ it hampers the detailed analysis of the ${ }^{13} \mathrm{C}$ or ${ }^{1} \mathrm{H}$ NMR line shape of the chain segments in the vicinity of the inorganic layers. Therefore, for these reasons, laponite, which is a synthetic clay, was considered in the present work. Lastly, even though a few weight percent of clay is enough to induce a significant increase of the Young modulus, we focused on PEO/laponite nanocomposites characterized by high filler loadings, above $50 \mathrm{wt} \%$ more precisely. Our aim is to get a neat intercalated phase, where all the PEO chains are confined within the interlayer galleries. In such a situation, the PEO chains should be fully amorphous ${ }^{38}$ and the PEO segmental dynamics in this amorphous phase is not affected by the occurrence of PEO crystallites: under these conditions, the influence of the clay platelets on the surrounding PEO chain segments can directly be probed. Besides, when the clay content is high enough, all the PEO monomer units are necessarily in the vicinity of a clay layer, so that $1 \mathrm{D}{ }^{13} \mathrm{C}$ and ${ }^{1} \mathrm{H}$ NMR experiments allow to investigate, in a straightforward way, the interfacial phenomena occurring at the laponite disc surfaces. As a result, the hybrid materials considered herein should be viewed as model systems, aimed at getting a better understanding of the chain dynamics in polymer/clay nanocomposites of applicative interests, i.e. characterized by clay contents of about $1-5 \mathrm{wt} \%$.

In a first step, the fraction of laponite required to avoid PEO crystallization will be estimated and the bulk organization of these hybrid materials in the solid state will be determined using differential scanning calorimetry (DSC) and X-ray scattering experiments. In a second step, we will investigate a PEO/laponite model system corresponding to fully amorphous PEO chains confined within the nanometer-thick galleries formed by the laponite platelets. We will address questions concerning the 
respective roles of chain confinement effects, which are expected to induce faster segmental motions than in the amorphous phase of the bulk PEO matrix, and attractive interactions of PEO chain segments with the hydrophilic laponite surfaces or complexation phenomena with the $\mathrm{Na}^{+}$cations located within the Van der Waals gaps, which should contribute to decrease the PEO segment motions. Since both confinement and polymer/clay surface or polymer $/ \mathrm{Na}^{+}$cation attractive interactions should result in large variations of the PEO chain segment mobility and opposite effects, the PEO segmental motions in the neat PEO/laponite intercalated phase will be monitored by taking advantage of the selectivity of solid-state NMR. ${ }^{13} \mathrm{C}$ and ${ }^{1} \mathrm{H}$ NMR experiments will be used to investigate the influence of the clay layers on the dynamical behaviour of the surrounding PEO monomer units over the microsecond time scale. Special attention will be paid to the study of the heterogeneous character displayed by the segmental dynamics of the PEO chains.

\section{Experimental Section.}

\subsection{Materials and Preparation.}

Poly(ethylene oxide) (PEO, Aldrich), characterized by gel permeation chromatography, has the following molecular characteristics: weight-average molecular weight $M_{\mathrm{w}}=123000$ g.mol ${ }^{-1}$, polydispersity index $I_{\mathrm{w}}=4.6$. The clay used in this work is Laponite RD (Laporte Industries Ltd), which is a 2:1 phyllosilicate with the following chemical composition: $\mathrm{Na}^{+}{ }_{0.7}\left[\left(\mathrm{Mg}_{5.5} \mathrm{Li}_{0.3}\right) \mathrm{Si}_{8} \mathrm{O}_{20}(\mathrm{OH})_{4}\right]^{-0.7}$. This is a synthetic clay and as such, it does not contain any paramagnetic $\mathrm{Fe}^{3+}$ species embedded in the clay platelets.

PEO/laponite nanocomposites were prepared using the exfoliation-adsorption technique. The detailed conditions of their elaboration are described elsewhere ${ }^{39}$ and only the main features are recalled here. Distilled water was used to form a suspension of laponite clay at a concentration of $1 \mathrm{wt} \%$. The suspension was stirred for $24 \mathrm{~h}$, with a control of both $\mathrm{pH}$ (maintained to 10) and ionic strength $(\mathrm{NaCl}$ concentration of $10^{-3}$ mol. $\left.1^{-1}\right)$. PEO homopolymer was then added, followed by a $24 \mathrm{~h}$ stirring period. The nanocomposites were then obtained by freeze-drying. The PEO/laponite materials considered in 
this work were characterized by a clay content of 50 and 70 wt $\%$ and will be denoted as $\mathrm{PEO} /$ laponite(50/50) and PEO/laponite(30/70) in the following.

Small-angle X-ray scattering (SAXS) experiments carried out on these samples, also reported elsewhere, ${ }^{39}$ showed the intercalation of the PEO chains in the silicate galleries, with a interlayer distance increasing from $0.94 \mathrm{~nm}$ (neat laponite) to $1.86 \mathrm{~nm}$ for both $\mathrm{PEO} /$ laponite nanocomposites. The first-order Bragg diffraction peak, related to the clay platelet stacking, was found to be narrower in the nanocomposite than in neat laponite. This feature suggests an increase of the orientational order locally displayed by the clay layers when blended with the PEO chains and is consistent with previous SAXS studies. ${ }^{38}$

\subsection{Solid-State NMR Experiments.}

Solid-state NMR experiments were carried out on a Bruker DSX 300 NMR spectrometer operating under a static magnetic field $H_{0}$ of $7.0 \mathrm{~T}$, equipped with a double-resonance MAS probe (4 $\mathrm{mm}$ rotors). The high-resolution ${ }^{13} \mathrm{C}$ NMR spectra were obtained using either ${ }^{1} \mathrm{H} \rightarrow{ }^{13} \mathrm{C}$ crosspolarization (CP) or ${ }^{13} \mathrm{C}$ direct polarization (DP) experiments. For the $\mathrm{CP}$-based experiments, a ${ }^{1} \mathrm{H} 90^{\circ}$ pulse width of $3.0 \mu \mathrm{s}$ and a recycle delay of $3 \mathrm{~s}$ were used. The ${ }^{1} \mathrm{H}$ field during the ${ }^{1} \mathrm{H} \rightarrow{ }^{13} \mathrm{C}$ magnetization transfer was set to $83 \mathrm{kHz}$. For ${ }^{13} \mathrm{C}$ direct polarization experiments, a ${ }^{13} \mathrm{C} 90^{\circ}$ pulse width of $3.2 \mu$ s and a recycle delay ranging between $4 \mathrm{~s}$ and $20 \mathrm{~s}$ were selected. The ${ }^{13} \mathrm{C}$-signal detection was performed under CW high-power proton decoupling (DD), with a RF field strength of $52 \mathrm{kHz}$. For most of the ${ }^{13} \mathrm{C}$ NMR experiments presented in this work, the sample spinning speed was set to $5 \mathrm{kHz}$. Occasionally, variations of the ${ }^{1} \mathrm{H}$ decoupling field strength (from 19 to $100 \mathrm{kHz}$ ) and the MAS spinning speed (from $2.5 \mathrm{kHz}$ to $9.0 \mathrm{kHz}$ ) were used to probe their influence on the PEO ${ }^{13} \mathrm{C}$ NMR line shape. The ${ }^{13} \mathrm{C}$ chemical shifts were calibrated relative to tetramethylsilane (TMS) by taking the ${ }^{13} \mathrm{C}$ chemical shift of the carbonyl peak of $\alpha$-glycine as an external reference standard (176.03 ppm with respect to TMS). ${ }^{1} \mathrm{H}$ NMR spectra under MAS conditions were recorded using a ${ }^{1} \mathrm{H} 90^{\circ}$ pulse width of $3.0 \mu$ s, a recycle delay of $10 \mathrm{~s}$ and a spinning speed of $5 \mathrm{kHz}$. Spin-lattice relaxation times in the laboratory 
frame, $T_{1}\left({ }^{1} \mathrm{H}\right)$, were measured using the inversion-recovery pulse sequence while spin-lattice relaxation times in the rotating frame, $T_{1 \rho}\left({ }^{1} \mathrm{H}\right)$, were determined with a $90^{\circ}$-spin lock experiment, the spin-locking field corresponding to $66 \mathrm{kHz}$. The ${ }^{1} \mathrm{H}$ chemical shift values were referenced using the methyl protons of ethanol as an external reference standard (1.11 ppm with respect to TMS).

1D ${ }^{13} \mathrm{C}$ and ${ }^{1} \mathrm{H}$ MAS NMR experiments were performed at variable temperatures, ranging from $70{ }^{\circ} \mathrm{C}$ up to $+100{ }^{\circ} \mathrm{C}$. The temperature calibration of the MAS probe used for these measurements was carried out by monitoring the ${ }^{207} \mathrm{~Pb}$ chemical shift of lead nitrate. ${ }^{40}$ Besides, the sample volume was restricted to the centre of the rotor in order to limit the effect of temperature gradients on ${ }^{13} \mathrm{C}$ and ${ }^{1} \mathrm{H}$ NMR line shapes.

2D ${ }^{1} \mathrm{H}-{ }^{1} \mathrm{H}$ correlation experiments were carried out at a MAS spinning speed of $9 \mathrm{kHz}$, with a ${ }^{1} \mathrm{H}$ $90^{\circ}$ pulse width of $2.8 \mu$ s and a recycle delay of $3 \mathrm{~s}$. A detailed description of this experiment, in the context of polymer/clay nanocomposites, can be found in reference 30. A frequency-switched LeeGoldburg ${ }^{1} \mathrm{H}-{ }^{1} \mathrm{H}$ decoupling at $89 \mathrm{kHz}$, with a ${ }^{1} \mathrm{H}$ resonance offset of $+/-59 \mathrm{kHz}$, was used during the evolution step. A variable mixing time $t_{\mathrm{m}}$ allowing ${ }^{1} \mathrm{H}$-driven spin-diffusion to take place was introduced before the detection of the ${ }^{1} \mathrm{H}$ NMR signal. The $t_{\mathrm{m}}$ values ranged between $5 \mu \mathrm{s}$ and $289 \mathrm{~ms}$.

\subsection{Differential Scanning Calorimetry (DSC).}

Differential scanning calorimetry experiments were performed on a TA Instruments DSC 2910 calorimeter. All the samples were submitted to the same thermal treatment: they were first heated at 100 ${ }^{\circ} \mathrm{C}$, let at this temperature for $5 \mathrm{~min}$ and cooled down to $-20^{\circ} \mathrm{C}$ at a cooling rate of $10{ }^{\circ} \mathrm{C} \cdot \mathrm{min}^{-1}$. Two consecutive heating and cooling scans from $-20{ }^{\circ} \mathrm{C}$ to $100{ }^{\circ} \mathrm{C}$ at $10{ }^{\circ} \mathrm{C} \cdot \mathrm{min}^{-1}$ were then recorded. These two heating scans were found to be identical, suggesting that no sample degradation or no evolution in the polymer/clay solid-state organization (in the case of the nanocomposites) occurred during the DSC experiments.

The degree of crystallinity of the PEO matrix was determined assuming a value of $188.6{\mathrm{~J} . \mathrm{g}^{-1}}^{1}$ for the heat of melting per unit mass of a $100 \%$ crystalline PEO sample. ${ }^{41}$ In the case of the PEO/laponite 
nanocomposites, the clay weight fraction was taken into account in the calculation of the degree of crystallinity.

\section{Results.}

\subsection{Solid-State Organization of PEO/Laponite Nanocomposites.}

Figure 1 shows the DSC thermograms obtained on the PEO/laponite(50/50) and PEO/laponite(30/70) nanocomposites, during the second heating scan. These samples were previously cooled from $100^{\circ} \mathrm{C}$ to $-20^{\circ} \mathrm{C}$, at a cooling rate of $10^{\circ} \mathrm{C} \cdot \mathrm{min}^{-1}$. The thermogram obtained on the corresponding PEO homopolymer with the same experimental conditions is also reported for the sake of comparison. Under the thermal history indicated previously, a melting peak $T_{\mathrm{m}}$ at $63^{\circ} \mathrm{C}$ with an enthalpy $\Delta H_{\mathrm{m}}$ of $145.0 \mathrm{~J} . \mathrm{g}^{-1}$ is observed on neat PEO, indicating that the PEO matrix is characterized by a degree of crystallinity of $77 \%$. Besides, the Gibbs-Thomson equation allows to get an estimate of the crystalline lamellae thickness of about $4.2 \mathrm{~nm} \cdot{ }^{42,43}$ In the PEO/laponite(50/50) nanocomposite submitted to the same thermal conditions, a PEO melting peak is also observed (Figure 1a), but the PEO matrix displays a smaller amount of crystallites (degree of crystallinity of $16 \%$ against $77 \%$ for neat PEO) while the crystalline lamellae thickness is reduced to $2.7 \mathrm{~nm}$. In contrast, in the PEO/laponite nanocomposite containing 70 wt \% of laponite, no PEO melting peak is detected in Figure $1 \mathrm{~b}$, which indicates that the PEO chains within this nanocomposite are amorphous. 
(a)

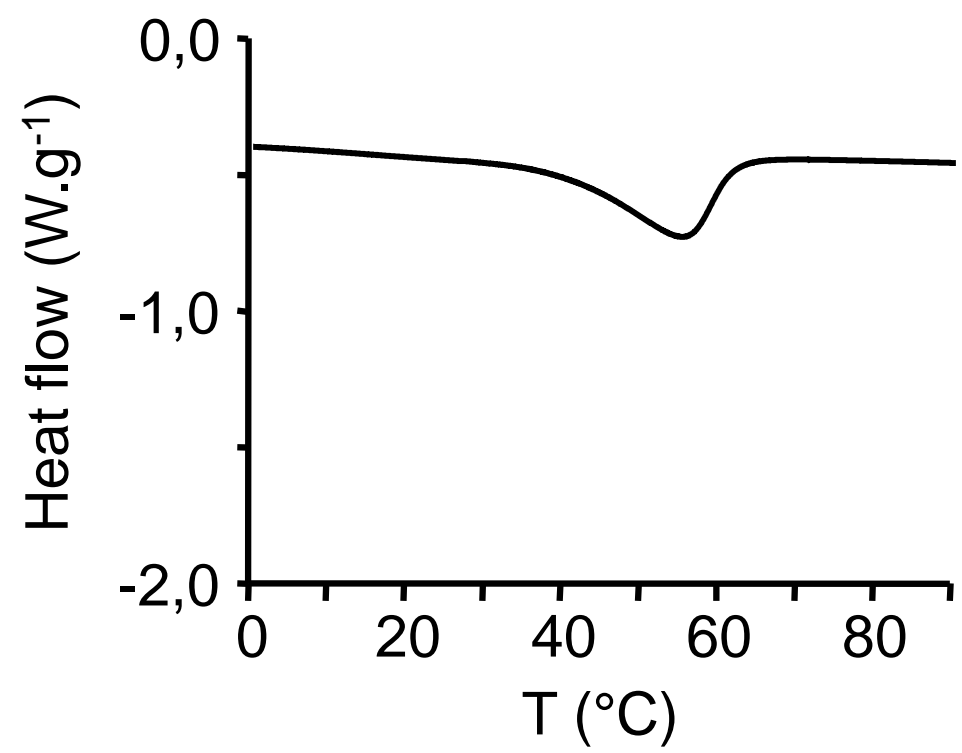

(b)

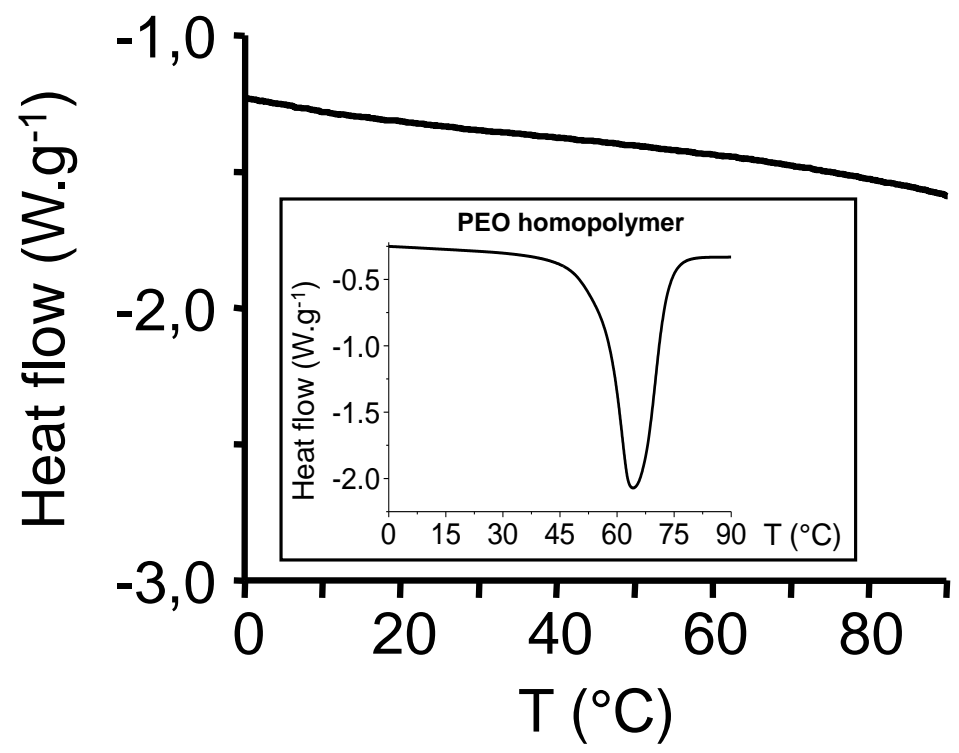

Figure 1. DSC thermograms recorded on (a) the PEO/laponite(50/50) nanocomposite, (b) the PEO/laponite(30/70) nanocomposite and on neat PEO (inset) during the second heating scan; the heating/cooling rate was set to $10{ }^{\circ} \mathrm{C} \cdot \mathrm{min}^{-1}$. The samples were previously cooled down to $-20{ }^{\circ} \mathrm{C}$ from the molten state, with a cooling rate of $10^{\circ} \mathrm{C} \cdot \mathrm{min}^{-1}$.

These observations are consistent with WAXS measurements performed on the same samples (Figure S1, Supporting Information). Indeed, Bragg diffraction peaks, characteristics of the monoclinic crystalline phase displayed by bulk PEO, can be observed on the diffractogram recorded on the PEO/laponite(50/50) nanocomposite, but the corresponding peaks are much less intense and significantly broader than in neat PEO. Both features are in agreement with the decrease of both 
cristallinity and crystalline lamellae thickness, respectively, deduced from the DSC measurements. As the laponite weight fraction is increased to $70 \mathrm{wt} \%$, the Bragg diffraction peaks related to PEO crystallites cannot be detected any longer on the WAXS diffractogram. Again, this result is consistent with the DSC experiments. Thus, with $70 \mathrm{wt} \%$ of laponite, all the PEO chains are mostly intercalated within the clay galleries and constitute a model system of amorphous chains confined to a narrow slit with a thickness of $0.96 \mathrm{~nm}$. In the following, the PEO segmental dynamics will be exclusively probed in the PEO/laponite(30/70) nanocomposite since the occurrence of PEO crystallites within the PEO/laponite(50/50) sample, even in small amount and even if these crystallites are rather small, may significantly affect the segmental dynamics of the PEO chain segments in the amorphous phase.

\subsection{Carbon-13 NMR Line Shapes.}

The ${ }^{13} \mathrm{C} \mathrm{CP} / \mathrm{MAS} / \mathrm{DD}$ NMR spectrum recorded on the neat $\mathrm{PEO}$ homopolymer at room temperature is reported in Figure 2a. The ${ }^{1} \mathrm{H} \rightarrow{ }^{13} \mathrm{C}$ contact time for this experiment was set to $1 \mathrm{~ms}$. A single ${ }^{13} \mathrm{C}$ NMR peak at $70.4 \mathrm{ppm}$ with a strong asymmetry in the high frequency side is observed. The ${ }^{13} \mathrm{C}$ NMR line shape of semi-crystalline PEO has already been studied in many details in the literature. ${ }^{44-46}$ Thus, in the following, only the features that are relevant for the present work will be reminded. The line observed in Figure 2a results from the overlap of two peaks: one located at about $71.0 \mathrm{ppm}$, related to the PEO monomer units in the amorphous regions, and one occurring about 1.0 ppm downfield, assigned to the PEO units involved in the crystallites. ${ }^{45,46}$ The degree of crystallinity of the PEO sample considered for the experiment shown in Figure 2a amounts to $77 \%$, as determined by DSC. Despite this rather high degree of crystallinity and the higher ${ }^{1} \mathrm{H} \rightarrow{ }^{13} \mathrm{C} \mathrm{CP}$ transfer efficiency in crystalline regions (compared to PEO amorphous zones, at room temperature), the contribution from the crystalline PEO monomer units is not detected as a clearly resolved peak, due to its significant spectral width. This feature was investigated thoroughly in reference 44 . One mechanism proposed to account for this result is based on the proton relaxation behaviour in the rotating frame, which is relevant during the ${ }^{1} \mathrm{H} \rightarrow{ }^{13} \mathrm{C} \mathrm{CP}$ transfer. Indeed, at this temperature, the $T_{1 \rho}\left({ }^{1} \mathrm{H}\right)$ relaxation signal measured on the neat 
PEO homopolymer considered in the present study is not monoexponential. The faster (longer) apparent $T_{\mathrm{lp}}\left({ }^{1} \mathrm{H}\right)$ component has been assigned to a dominant amount of crystalline (amorphous) domains. ${ }^{45,46} \mathrm{In}$ a ${ }^{13} \mathrm{C}$ CP/MAS/DD NMR experiment, during the ${ }^{1} \mathrm{H} \rightarrow{ }^{13} \mathrm{C}$ CP transfer, this $T_{1 \rho}\left({ }^{1} \mathrm{H}\right)$ relaxation feature tends to lower the amplitude of the ${ }^{13} \mathrm{C}$ peak of crystalline PEO monomer units compared to the spectral contribution of the amorphous PEO carbons.

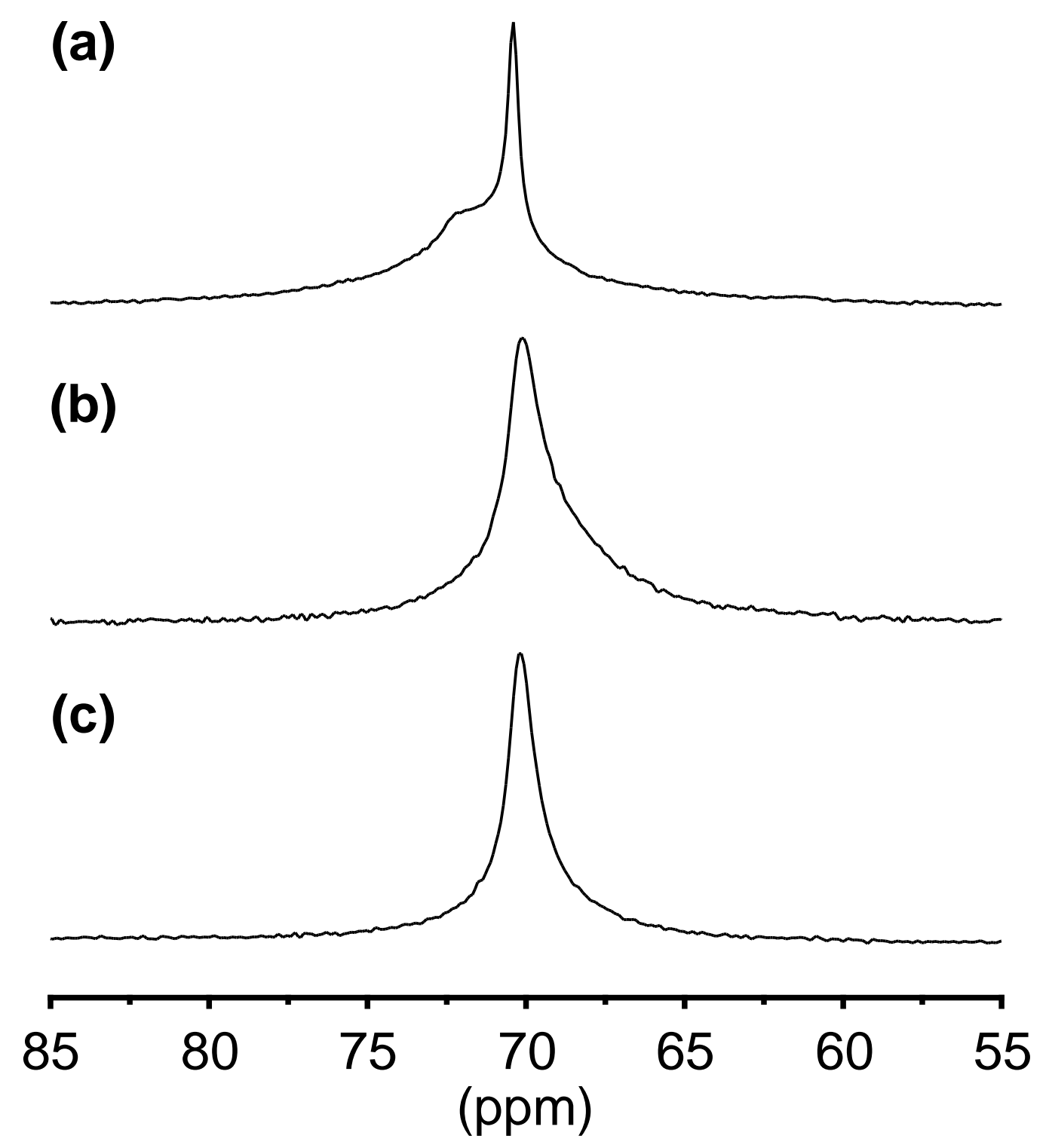

Figure 2. ${ }^{13} \mathrm{C}$ CP/MAS/DD NMR spectra of: (a) neat PEO and (b) PEO/laponite(30/70) nanocomposite; the ${ }^{1} \mathrm{H} \rightarrow{ }^{13} \mathrm{C} \mathrm{CP}$ contact time was set to $1 \mathrm{~ms}$. (c) ${ }^{13} \mathrm{C}$ DP/MAS/DD spectrum obtained on the PEO/laponite(30/70) nanocomposite; a recycle delay of $20 \mathrm{~s}$ was used for this experiment. All these spectra were recorded at room temperature. 
Figure $2 \mathrm{~b}$ depicts the ${ }^{13} \mathrm{C} \mathrm{CP} / \mathrm{MAS} / \mathrm{DD}$ NMR spectrum obtained with a contact time of $1 \mathrm{~ms}$ on the PEO/laponite(30/70) nanocomposite, at room temperature. The ${ }^{13} \mathrm{C}$ NMR peak observed under these experimental conditions occurs at about $70.2 \mathrm{ppm}$ and thus displays a weak upfield shift compared to the contribution of amorphous PEO carbons in the semi-crystalline PEO matrix described above. A deeper analysis of the ${ }^{13} \mathrm{C}$ chemical shift displayed by the PEO carbons in the intercalated phase will be carried out in the following of this work. Besides, interestingly, the ${ }^{13} \mathrm{C}$ NMR peak observed in the nanocomposite is not symmetric and displays a pronounced asymmetry in the low frequency side. This feature cannot be assigned to the contribution of PEO monomer units involved in crystalline regions, in contrast to the asymmetry observed under the same experimental conditions on the ${ }^{13} \mathrm{C}$ NMR line of neat PEO. Indeed, both DSC and WAXS experiments presented above have shown that due to the high clay content used, the PEO chains within the nanocomposite are fully amorphous. In addition, the frequency location of the asymmetry observed in Figure $2 \mathrm{~b}$ is not compatible with the ${ }^{13} \mathrm{C}$ chemical shift of crystalline PEO carbons (Figure 2a). Additional ${ }^{13} \mathrm{C}$ NMR experiments have been carried out to get a deeper understanding of the PEO ${ }^{13} \mathrm{C}$ NMR line shape in the nanocomposite.

The ${ }^{13} \mathrm{C} \mathrm{CP/MAS/DD} \mathrm{NMR} \mathrm{spectrum} \mathrm{of} \mathrm{the} \mathrm{PEO/laponite} \mathrm{intercalated} \mathrm{phase} \mathrm{may} \mathrm{be} \mathrm{compared} \mathrm{to}$ the ${ }^{13} \mathrm{C}$ NMR spectrum obtained using a direct polarization (DP) experiment, reported in Figure 2c. In the DP/MAS/DD spectrum, the chemical shift of the peak related to the PEO units displays a slight upfield shift (less than $0.1 \mathrm{ppm}$ ) compared to the PEO contribution observed on the CP/MAS/DD spectrum. Moreover, the $\mathrm{PEO}{ }^{13} \mathrm{C}$ peak is much narrower than in the ${ }^{13} \mathrm{C} \mathrm{CP} / \mathrm{MAS} / \mathrm{DD}$ NMR spectrum shown in Figure $2 \mathrm{~b}(88 \mathrm{~Hz}$ against $126 \mathrm{~Hz})$ and the asymmetry is less pronounced. At this stage, it is of interest to recall that under the direct polarization conditions, all the PEO carbons equally contribute to the ${ }^{13} \mathrm{C}$ NMR line. In contrast, in ${ }^{1} \mathrm{H} \rightarrow{ }^{13} \mathrm{C} \mathrm{CP}$-based experiments, the contribution of a given carbon to ${ }^{13} \mathrm{C}$ NMR peak depends on the strength of the heteronuclear ${ }^{1} \mathrm{H}-{ }^{13} \mathrm{C}$ dipolar couplings, but also on the spin-lattice relaxation time in the rotating frame $T_{1 \rho}\left({ }^{1} \mathrm{H}\right)$ involved by the protons surrounding this carbon. Therefore, in the PEO/laponite(30/70) nanocomposite, the difference in the ${ }^{13} \mathrm{C}$ NMR line shape 
related to the PEO carbons observed between DP/MAS/DD and CP/MAS/DD spectra may be explained by a strong distribution of the ${ }^{1} \mathrm{H}-{ }^{13} \mathrm{C}$ dipolar couplings occurring within the intercalated $\mathrm{PEO}$ monomer units and/or a non-uniform $T_{1 \rho}\left({ }^{1} \mathrm{H}\right)$ relaxation behaviour among the PEO protons. PEO carbons displaying a significant distribution of ${ }^{1} \mathrm{H}-{ }^{13} \mathrm{C}$ dipolar couplings would necessarily result from a pronounced heterogeneity in the segmental motions of the PEO chains confined between the laponite discs.

At this stage, it is of interest to consider the spin-lattice relaxation of the protons in the PEO/laponite(30/70) nanocomposite, in both laboratory $\left(T_{1}\left({ }^{1} \mathrm{H}\right)\right)$ and rotating $\left(T_{1 \rho}\left({ }^{1} \mathrm{H}\right)\right)$ frames. At a MAS spinning speed of $5 \mathrm{kHz}$, the ${ }^{1} \mathrm{H}$ NMR peak at $3.6 \mathrm{ppm}$, related to the PEO protons, is rather wellseparated from the one assigned to the laponite $\mathrm{OH}$ protons, located at $0.2 \mathrm{ppm}$. Thus, the ${ }^{1} \mathrm{H}$ spin-lattice relaxation signals, reported in Figure 3, were measured under MAS conditions, using the height of both PEO and laponite ${ }^{1} \mathrm{H}$ NMR peaks. Considering the height, instead of the area under the NMR peaks, enables to minimize the effect of their overlap on the ${ }^{1} \mathrm{H}$ relaxation signals. As can be seen in Figure 3a, the $T_{1}\left({ }^{1} \mathrm{H}\right)$ relaxation function determined on both $\mathrm{PEO}$ and laponite ${ }^{1} \mathrm{H}$ peaks are identical and can be described by a single-exponential decay, with $T_{1}\left({ }^{1} \mathrm{H}\right)=0.25$ s. This result indicates that the ${ }^{1} \mathrm{H}$ magnetization related to the PEO chains fully equilibrates with the one of the clay $\mathrm{OH}$ protons on the $T_{1}\left({ }^{1} \mathrm{H}\right)$ time scale. In contrast, the $T_{1 \rho}\left({ }^{1} \mathrm{H}\right)$ relaxation decay of the PEO protons does not superimpose with the one obtained for the clay protons, as shown in Figure $3 b$. Such a difference shows that complete equilibration of the proton magnetization related to PEO and laponite components does not occur on the $T_{1 \rho}\left({ }^{1} \mathrm{H}\right)$ time scale. In addition, the $T_{1 \rho}\left({ }^{1} \mathrm{H}\right)$ relaxation is not monoexponential, but can be described using two distinct $T_{1 \rho}\left({ }^{1} \mathrm{H}\right)$ components: $T_{1 \rho, \mathrm{s}}\left({ }^{1} \mathrm{H}\right)=1.5 \mathrm{~ms}$ and $T_{1 \rho, 1}\left({ }^{1} \mathrm{H}\right)=5.3 \mathrm{~ms}$ for the relaxation signal obtained using the height of the PEO ${ }^{1} \mathrm{H}$ peak. The amplitude related to the faster $T_{1 \rho}\left({ }^{1} \mathrm{H}\right)$ relaxing component of the signal determined on the PEO ${ }^{1} \mathrm{H}$ peak is of about $41 \%$. This latter is much more intense than the peak of the laponite $\mathrm{OH}$ protons so that the partial overlap of both peaks is not sufficient to account for the biexponential feature of the $T_{1 \rho}\left({ }^{1} \mathrm{H}\right)$ relaxation function determined at $3.6 \mathrm{ppm}$. 

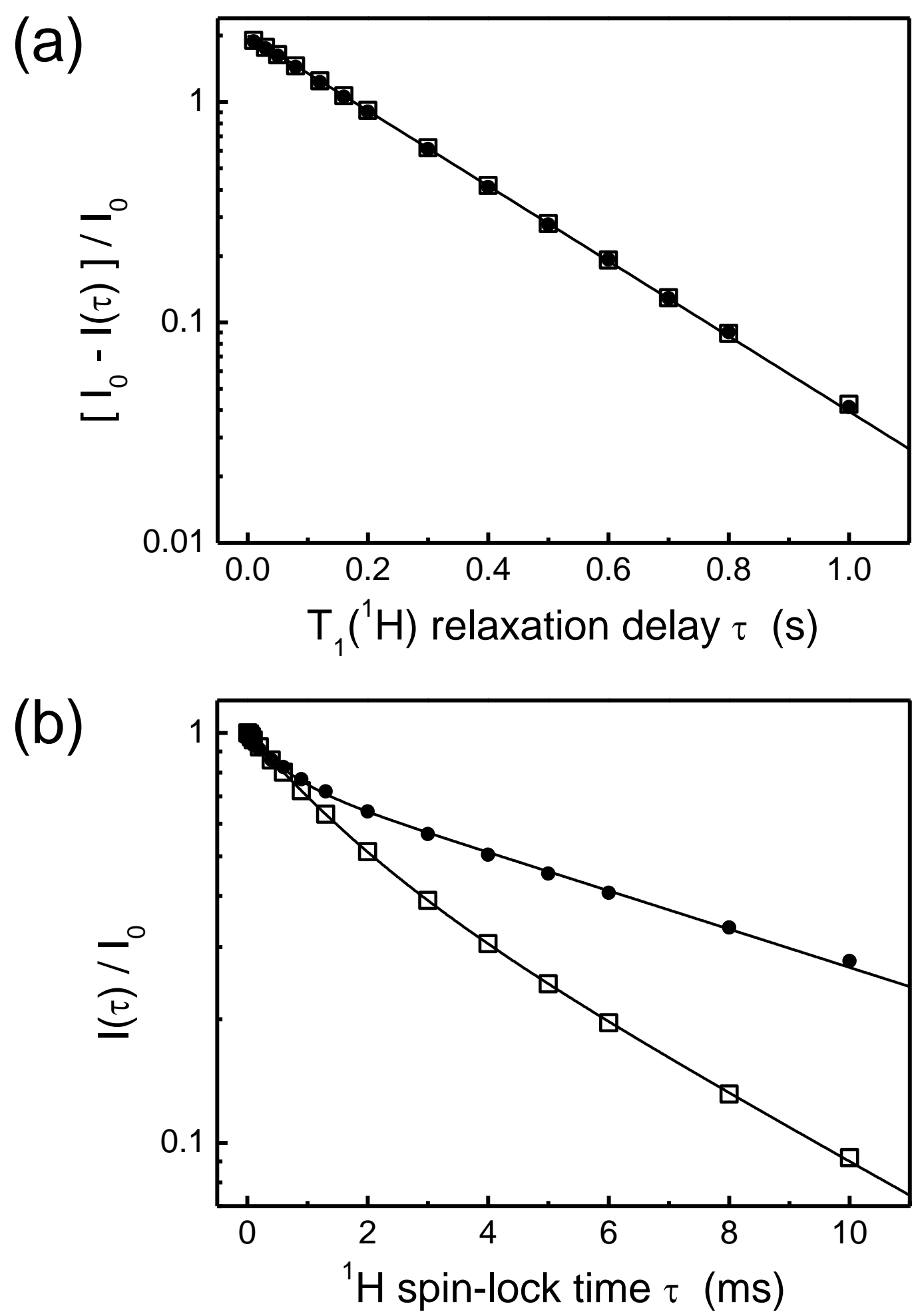

Figure 3. Proton spin-lattice relaxation (a) in the laboratory frame, (b) in the rotating frame, measured on both PEO/laponite(30/70) nanocomposite components: ( $\square$ ) PEO protons and ( $($ ) laponite $\mathrm{OH}$ protons. The relaxation decays were deduced from the height $I$ of both PEO and clay proton peaks, observed under MAS conditions (spinning speed of $5 \mathrm{kHz}$ ). The data were normalized by $I_{0}$, the proton magnetization at full equilibrium, under the static NMR magnetic field $H_{0}$. 
Non-uniform $T_{1 \rho}\left({ }^{1} \mathrm{H}\right)$ relaxation behaviour among the PEO monomer units may be induced by dynamical heterogeneities in the PEO segmental motions within the laponite galleries, leading to distinct contributions to the spectral density in the upper-kilohertz region $(66 \mathrm{kHz}$, the intensity of the ${ }^{1} \mathrm{H}$ spin-lock field used, expressed in frequency unit). However, the effect of ${ }^{1} \mathrm{H}$-driven spin-diffusion should also be taken into account to interpret the $T_{1 \rho}\left({ }^{1} \mathrm{H}\right)$ relaxation behaviour of the PEO protons. In particular, the longer $T_{1 \rho}\left({ }^{1} \mathrm{H}\right)$ decay may be related to ${ }^{1} \mathrm{H}$-driven spin-diffusion from the protons of the laponite platelets. Thus, at this stage, the origin of the non-uniform $T_{1 \rho}\left({ }^{1} \mathrm{H}\right)$ relaxation of the PEO protons cannot be unambiguously determined. However, one important point to go further in the analysis of the ${ }^{13} \mathrm{C} \mathrm{CP} / \mathrm{MAS} / \mathrm{DD}$ NMR spectrum of the nanocomposite is that the faster $T_{1 \rho}\left({ }^{1} \mathrm{H}\right)$ relaxing component is longer than the ${ }^{1} \mathrm{H} \rightarrow{ }^{13} \mathrm{C}$ contact time of $1 \mathrm{~ms}$ used for the spectrum reported in Figure 2b. Thus, after the CP step, the amplitude of the short (long) $T_{1 \rho}\left({ }^{1} \mathrm{H}\right)$ decay measured at $3.6 \mathrm{ppm}$ is reduced to about $50 \%(83 \%)$ of its initial value and one might expect that the non-uniform $T_{1 \rho}\left({ }^{1} \mathrm{H}\right)$ decay of the PEO protons is not strong enough to account for the differences in the ${ }^{13} \mathrm{C}$ NMR line shape detected between CP/MAS/DD and DP/MAS/DD spectra.

In order to confirm the previous assumption, ${ }^{13} \mathrm{C} \mathrm{CP} / \mathrm{MAS} / \mathrm{DD}$ NMR spectra were recorded on the intercalated PEO chains for various ${ }^{1} \mathrm{H} \rightarrow{ }^{13} \mathrm{C}$ contact times, $t_{\mathrm{CP}}$, and representative results are plotted in Figure 4. Let us first consider the results obtained using $t_{\mathrm{CP}}$ values that are small compared to the faster $T_{1 \rho}\left({ }^{1} \mathrm{H}\right)$ relaxing component determined for the PEO protons, namely $t_{\mathrm{CP}}=20$ and $100 \mu \mathrm{s}$. For these contact time values, the $\mathrm{PEO}{ }^{13} \mathrm{C}$ line shape also displays strong differences with the one observed on the DP/MAS/DD spectrum of Figure 2c. This feature clearly evidences that the non-uniform $T_{1 \rho}\left({ }^{1} \mathrm{H}\right)$ relaxation of the PEO protons is not enough to account for the differences between ${ }^{13} \mathrm{C} \mathrm{CP/MAS/DD}$ and DP/MAS/DD spectra of the nanocomposite obtained at room temperature. As a consequence, in the $\mathrm{PEO} /$ laponite intercalated phase, it must exist a significant distribution of the ${ }^{1} \mathrm{H}-{ }^{13} \mathrm{C}$ dipolar couplings among the PEO chain segments, corresponding to a strong heterogeneity in the PEO segmental motions. 


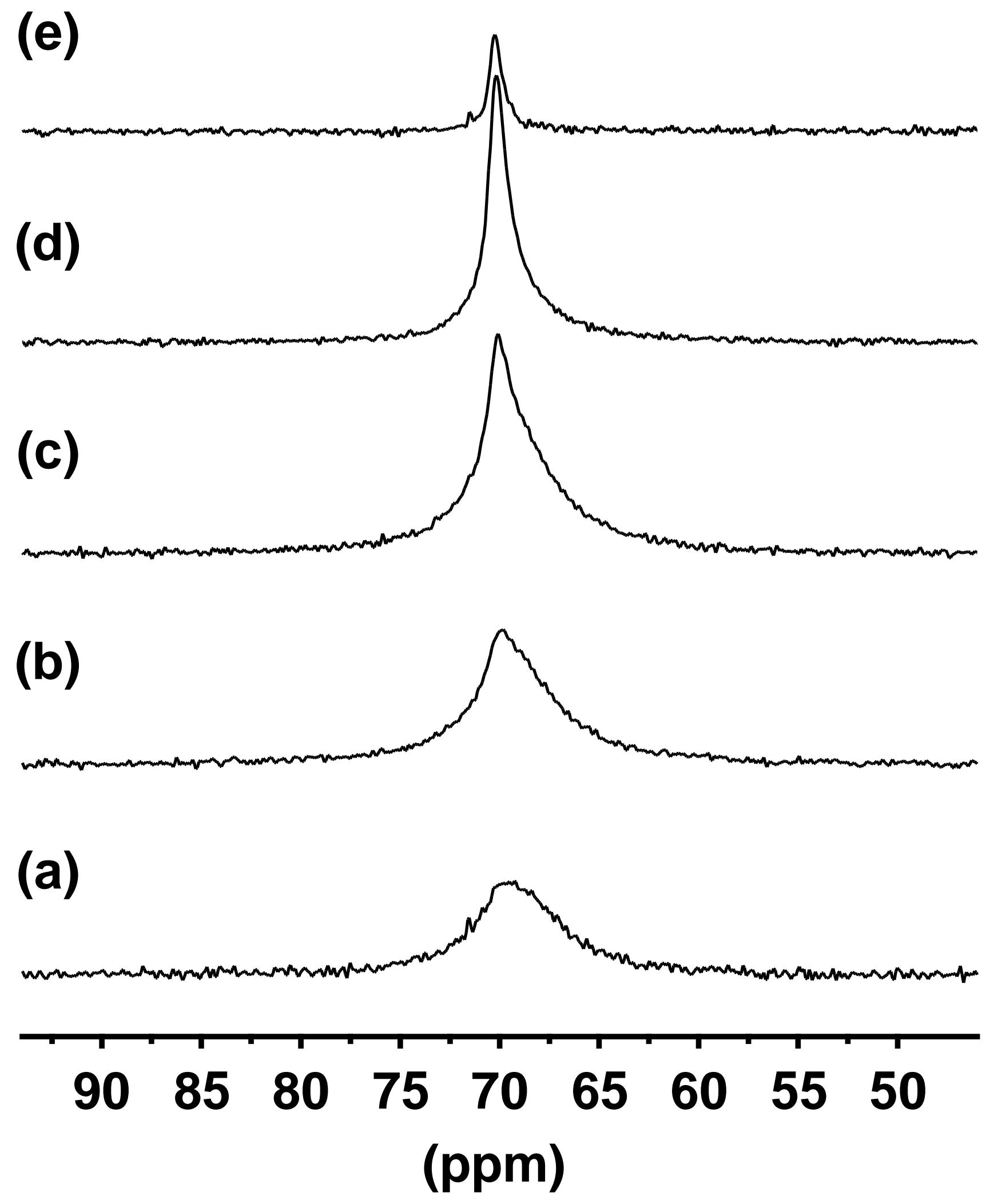

Figure 4. ${ }^{13} \mathrm{C} \mathrm{CP} / \mathrm{MAS} / \mathrm{DD} \mathrm{NMR}$ spectra of the $\mathrm{PEO} /$ laponite(30/70) nanocomposite obtained for various values of the ${ }^{1} \mathrm{H} \rightarrow{ }^{13} \mathrm{C}$ contact time, $t_{\mathrm{CP}}$ : (a) $20 \mu \mathrm{s}$, (b) $100 \mu \mathrm{s}$, (c) $400 \mu \mathrm{s}$, (d) $2 \mathrm{~ms}$ and (e) 10 ms. 
Considering now the variations of the ${ }^{13} \mathrm{C}$ NMR line shape with the ${ }^{1} \mathrm{H} \rightarrow{ }^{13} \mathrm{C}$ contact time (Figure 4), one may note that for short $t_{\mathrm{CP}}$ values $(20 \mu \mathrm{s}$ for instance), the peak is rather broad (half-height line width $\delta v_{1 / 2}$ of $351 \mathrm{~Hz}$ ) and symmetric. As $t_{\mathrm{CP}}$ is increased, the ${ }^{13} \mathrm{C} \mathrm{NMR}$ peak gets narrower, the asymmetry is more and more pronounced and a low field shift of the peak is also observed. Figure 5 depicts the evolution of both line width at mid-height $\delta v_{1 / 2}$ and ${ }^{13} \mathrm{C}$ chemical shift $\delta$ with the ${ }^{1} \mathrm{H} \rightarrow{ }^{13} \mathrm{C}$ contact time. Both parameters tend to a constant value for $t_{\mathrm{CP}}$ higher than $2 \mathrm{~ms}$. Therefore, the analysis of the variation of the PEO line shape in the nanocomposite with the ${ }^{1} \mathrm{H} \rightarrow{ }^{13} \mathrm{C}$ contact time enables to rationalize the asymmetric ${ }^{13} \mathrm{C}$ line shape initially observed on the ${ }^{13} \mathrm{C} \mathrm{CP} / \mathrm{MAS} / \mathrm{DD} \mathrm{NMR}$ spectrum obtained with a contact time of $1 \mathrm{~ms}$ (Figure $2 \mathrm{~b}$ ). The upfield asymmetry results from the superposition of different contributions related to $\mathrm{PEO}$ chain segments characterized by distinct ${ }^{1} \mathrm{H}-{ }^{13} \mathrm{C}$ dipolar couplings and so, distinct segmental mobility, as well as distinct chemical shifts: the lower the dipolar couplings (and thus the higher the segmental mobility), the higher the ${ }^{13} \mathrm{C}$ chemical shift.

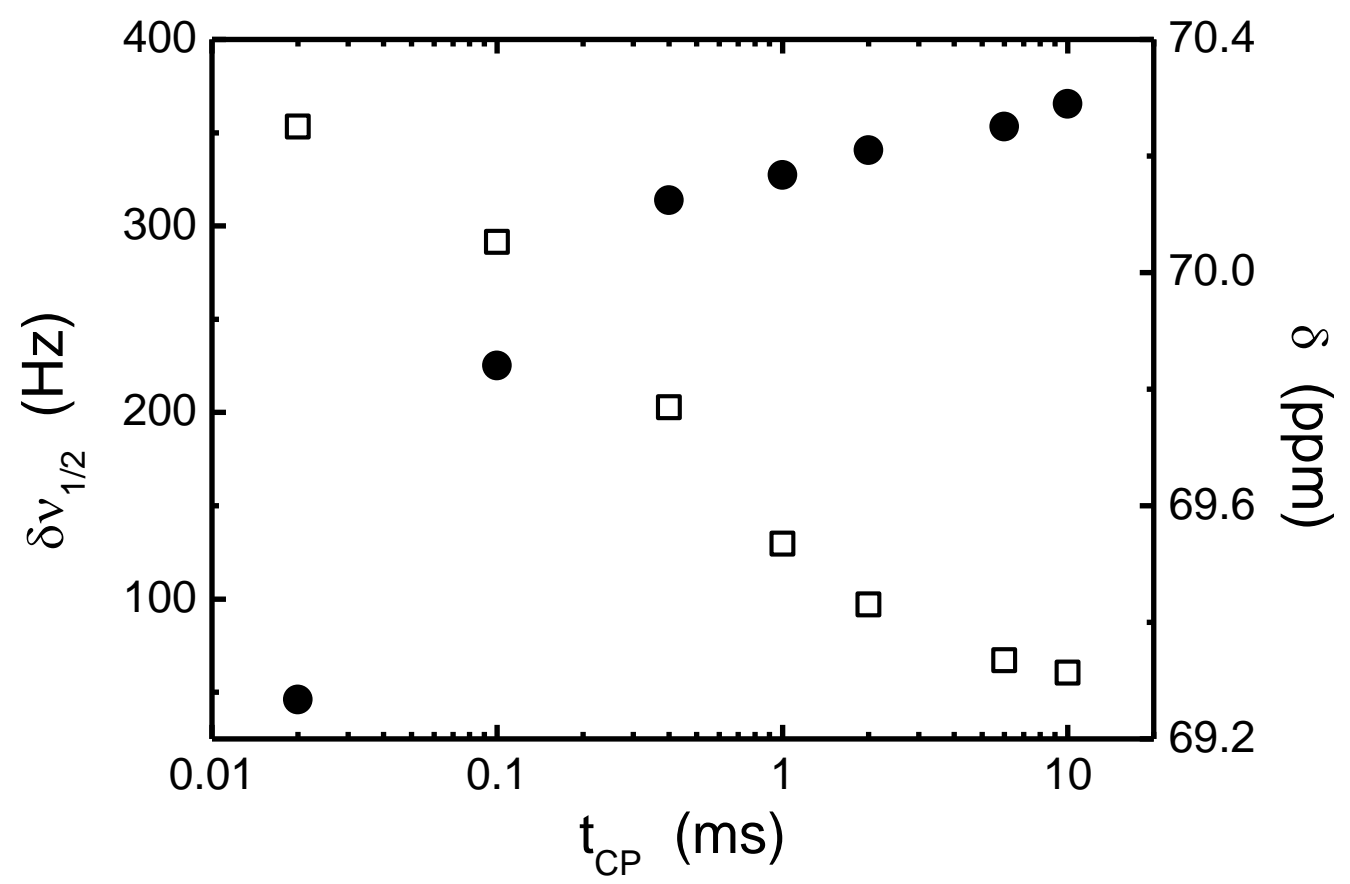

Figure 5. Variation of the half-height line width $\delta v_{1 / 2}(\square)$ and the chemical shift $\delta(\bigcirc)$ of the PEO ${ }^{13} \mathrm{C}$ NMR peak with the ${ }^{1} \mathrm{H} \rightarrow{ }^{13} \mathrm{C}$ contact time $t_{\mathrm{CP}}$. These values were measured on the ${ }^{13} \mathrm{C}$ NMR spectra of the nanocomposite, recorded through ${ }^{1} \mathrm{H} \rightarrow{ }^{13} \mathrm{C} \mathrm{CP} / \mathrm{MAS} / \mathrm{DD}$ NMR experiments. 
Having this interpretation in mind, one should expect the heterogeneous dynamical behaviour of the PEO chain segments, observed at room temperature, to disappear at sufficiently high temperature. Thus, both ${ }^{13} \mathrm{C}$ CP/MAS/DD and DP/MAS/DD NMR spectra were recorded on the PEO/laponite(30/70) nanocomposite, at $373 \mathrm{~K}$. For the ${ }^{13} \mathrm{C} \mathrm{CP} / \mathrm{MAS} / \mathrm{DD} \mathrm{NMR}$ experiment, a contact time of $1 \mathrm{~ms}$ was selected. At this temperature, both spectra are identical, as can be seen on Figure 6.

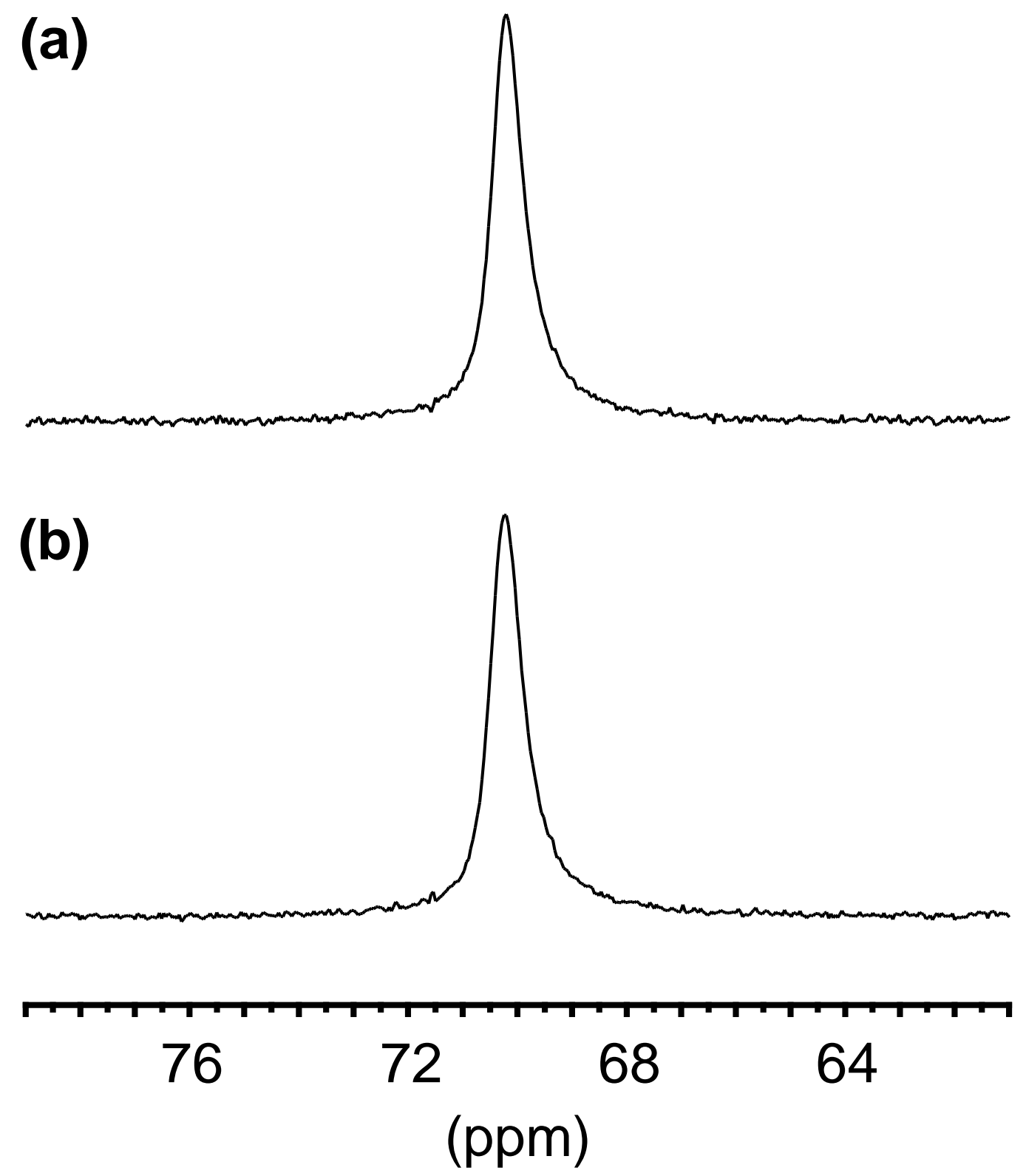

Figure 6. Comparison of the ${ }^{13} \mathrm{C}$ NMR spectra obtained at $373 \mathrm{~K}$ on the PEO/laponite(30/70) nanocomposite using: (a) ${ }^{1} \mathrm{H} \rightarrow{ }^{13} \mathrm{C} \mathrm{CP} / \mathrm{MAS} / \mathrm{DD}$ experiment, with a contact time $t_{\mathrm{CP}}$ of $1 \mathrm{~ms}$, (b) ${ }^{13} \mathrm{C}$ DP/MAS/DD NMR experiment. 
This result demonstrates that at $373 \mathrm{~K}$, all the PEO chain segments display similar values of the ${ }^{1} \mathrm{H}-{ }^{13} \mathrm{C}$ dipolar couplings and thus, very close segmental mobilities. Increasing the temperature by about $80 \mathrm{~K}$ leads to the suppression of the pronounced heterogeneities in the PEO segmental motions detected at room temperature, as expected from our analysis of the data obtained at room temperature. It is worth remarking that, in the $\mathrm{PEO} /$ laponite(30/70) nanocomposite, the chemical shift of the PEO ${ }^{13} \mathrm{C} \mathrm{NMR}$ peak is the same at room temperature and at $373 \mathrm{~K}$. Only the upfield asymmetry has disappeared at high temperature. This last feature is consistent with the dependence of the ${ }^{13} \mathrm{C} C P / \mathrm{MAS} / \mathrm{DD}$ NMR spectra with the CP contact time, observed at room temperature.

Complementary information on the PEO segmental dynamics in the PEO/laponite intercalated phase can be derived by monitoring the ${ }^{13} \mathrm{C}$ NMR line shape variation as a function of temperature. Illustrative ${ }^{13} \mathrm{C}$ DP/MAS/DD NMR spectra recorded on the PEO/laponite(30/70) nanocomposite for various temperatures between $335 \mathrm{~K}$ and $203 \mathrm{~K}$ are shown in Figure 7 and the corresponding temperature dependence of the half-height line width $\delta v_{1 / 2}$ is reported in Figure 8. For comparison, the evolution of $\delta v_{1 / 2}$ with the temperature for amorphous monomer units of neat PEO is also plotted in Figure 8. Though bulk PEO is a semi-crystalline matrix, the selective observation of the amorphous phase is achieved by taking advantage of the difference in the $T_{1}\left({ }^{13} \mathrm{C}\right)$ value displayed by both crystalline and amorphous phases. ${ }^{47}$ Thus, as $T_{1}\left({ }^{13} \mathrm{C}\right)$ is much higher for PEO crystalline carbons than for amorphous PEO monomer units, ${ }^{13} \mathrm{C}$ DP/MAS/DD NMR spectra recorded with intermediate recycle delays enable to probe, selectively, the amorphous phase. Spectra obtained under these conditions (recycle delays of $0.6 \mathrm{~s}$ ) were used to determine the $\delta v_{1 / 2}(T)$ values reported in Figure 8.

Let us first consider the data related to the $\mathrm{PEO} /$ laponite intercalated phase. From $335 \mathrm{~K}$ down to $305 \mathrm{~K}, \delta v_{1 / 2}$ remains nearly constant, with a value of $73 \mathrm{~Hz}$ at $305 \mathrm{~K}$. More precisely, a very weak increase of the line width is observed as the temperature is decreased in this range, but it can be neglected compared to the pronounced line broadening occurring from $73 \mathrm{~Hz}$ at $305 \mathrm{~K}$ up to $472 \mathrm{~Hz}$ at $243 \mathrm{~K}$. The half-height line width reaches a maximum at $243 \mathrm{~K}$ and a further temperature decrease 
induces a line narrowing until $223 \mathrm{~K}$. From $223 \mathrm{~K}$ to $203 \mathrm{~K}$, which is the lowest temperature that was reached experimentally under the MAS conditions, $\delta v_{1 / 2}$ remains nearly unchanged.

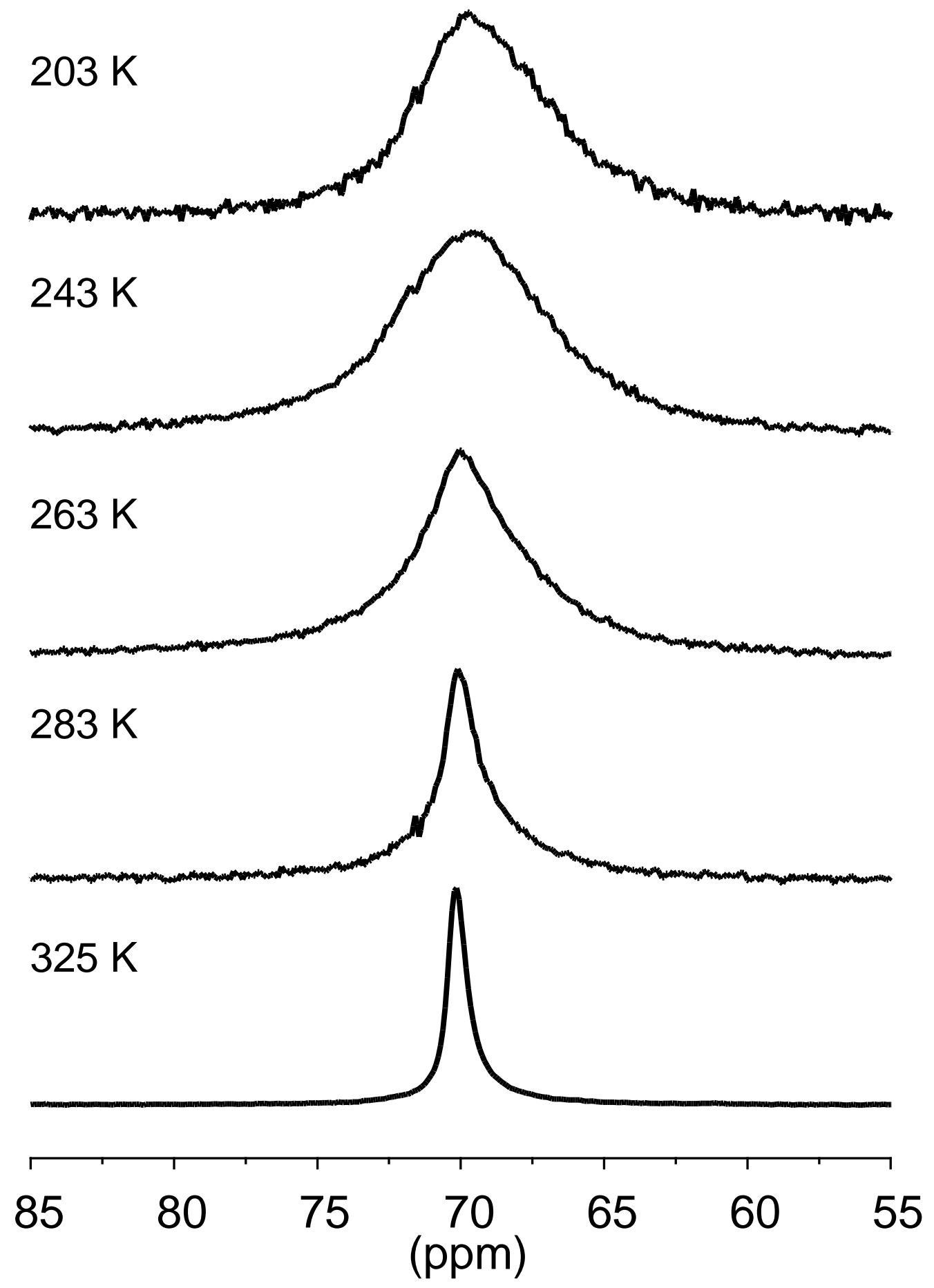

Figure 7. ${ }^{13} \mathrm{C}$ DP/MAS/DD NMR spectra obtained on the PEO/laponite(30/70) nanocomposite for temperatures ranging between $335 \mathrm{~K}$ and $203 \mathrm{~K}$. The MAS spinning speed was set to $5 \mathrm{kHz}$ and the intensity of the $\mathrm{CW}$ proton decoupling during the ${ }^{13} \mathrm{C}$-signal acquisition, to $52 \mathrm{kHz}$. 


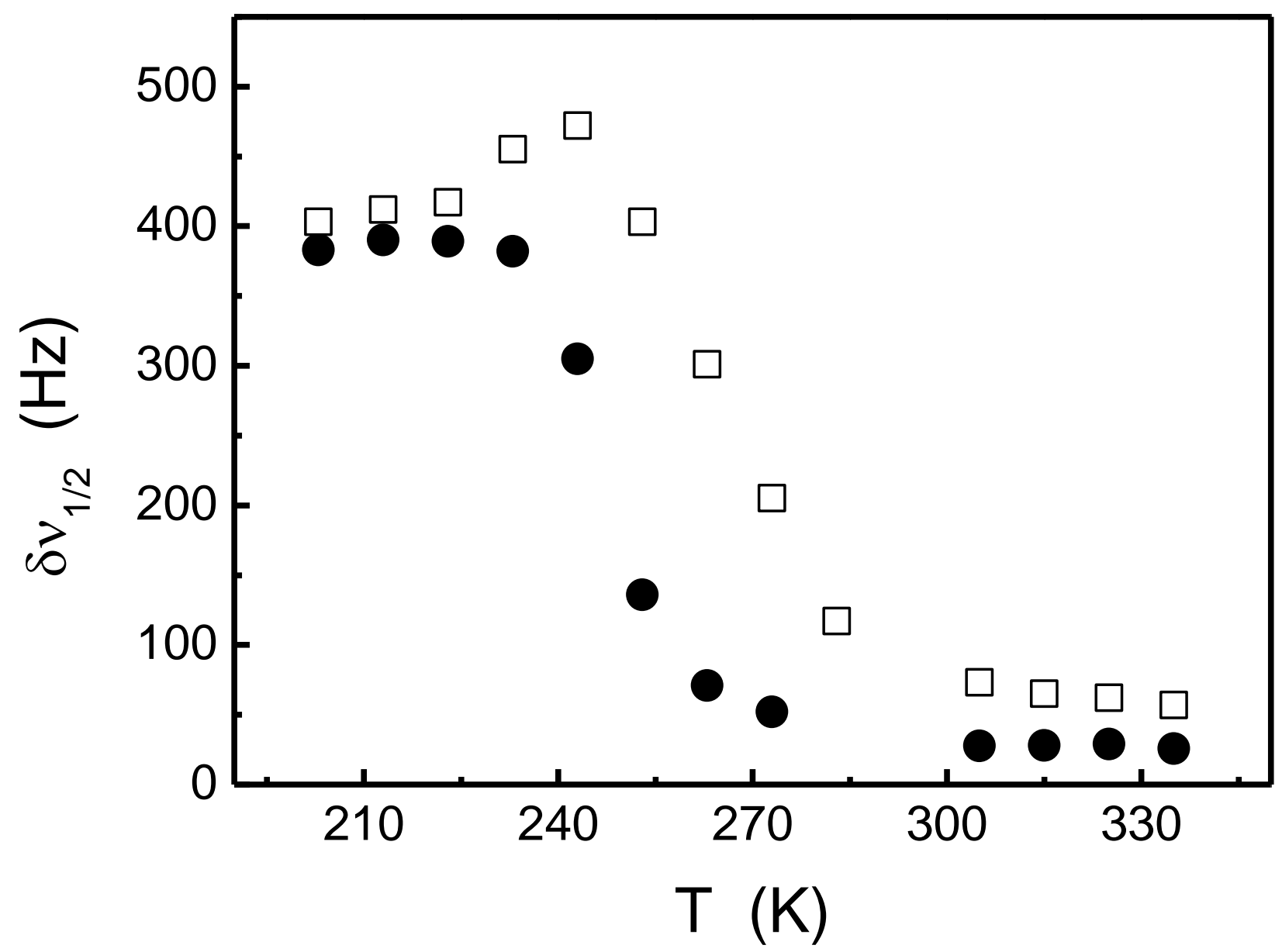

Figure 8. Temperature dependence of the half-height line width $\delta v_{1 / 2}$ of the PEO ${ }^{13} \mathrm{C}$ NMR peak measured on the DP/MAS/DD spectra obtained for the PEO/laponite(30/70) nanocomposite ( $\square$ ) and for neat PEO (-). In the case of the neat semi-crystalline PEO matrix, a short recycle delay was used to probe selectively amorphous chain segments.

The global line width reduction from low $(203 \mathrm{~K})$ to high $(335 \mathrm{~K})$ temperatures may be assigned to the crossover from the glassy to the molten state of the PEO chains intercalated within the clay platelets ( $\alpha$-relaxation). The same explanation holds for the data obtained on amorphous monomer units of bulk PEO. In the glassy state, the frozen chain conformations as well as the variations in the interchain packing induce a dispersion of the ${ }^{13} \mathrm{C}$ chemical shift values related to the PEO carbons. Far above the glass transition, such a dispersion is strongly reduced due to a strong motional averaging effect. In particular, in the molten state, one significant contribution to the ${ }^{13} \mathrm{C}$ line width may origin 
from the local magnetic field inhomogeneities. In the present case, the contrast between the diamagnetic susceptibility of the clay layers and the one related to the PEO chains may contribute to NMR magnetic field inhomogeneities which could be experienced by some PEO carbons. Experimentally, the line width at the high temperature plateau of the $\delta v_{1 / 2}(T)$ variation is more than two times higher for the PEO/laponite(30/70) nanocomposite than for amorphous chain segments of the neat PEO homopolymer. Such a difference may result from the diamagnetic susceptibility contrast effects mentioned above as well as differences in the PEO segmental dynamics between both samples, remaining up to $335 \mathrm{~K}$.

From another point of view, the additional line broadening detected around $243 \mathrm{~K}$ on Figure 8 may be ascribed to the modulation of the ${ }^{1} \mathrm{H}-{ }^{13} \mathrm{C}$ dipolar couplings by the molecular motions of the PEO chain segments in the intercalated phase ${ }^{44,48}$ More precisely, as the characteristic frequency of the PEO $\mathrm{C}-\mathrm{H}$ bond motions matches the intensity of the ${ }^{1} \mathrm{H}$ decoupling field, expressed in frequency unit, interference effects between the motional modulation of the ${ }^{1} \mathrm{H}-{ }^{13} \mathrm{C}$ dipolar couplings and the coherent modulation of the ${ }^{1} \mathrm{H}$ decoupling field lead to an increase of the line width of the PEO ${ }^{13} \mathrm{C}$ NMR peak. Another dynamic line broadening mechanism, related to the modulation of the chemical shift anisotropy of the PEO carbons, could be invoked to account for the line broadening around $243 \mathrm{~K}$ observed in Figure 8. Such a motional modulation may interfere with the coherent modulation induced by MAS, as soon as the characteristic frequency of the reorientational motions displayed by the PEO carbons is equal to the MAS spinning speed $v_{\mathrm{r}}{ }^{44,49}$ To check whether this line broadening mechanism is responsible for the temperature dependence of $\delta v_{1 / 2}$ around $243 \mathrm{~K}$, a ${ }^{13} \mathrm{C}$ DP/MAS/DD NMR spectrum was recorded on the $\mathrm{PEO} /$ laponite(30/70) nanocomposite at this temperature, using a different value of the MAS spinning speed: $2.5 \mathrm{kHz}$. No significant variation in the PEO ${ }^{13} \mathrm{C}$ NMR line shape was detected when comparing this spectrum with the one obtained at the same temperature, with a spinning speed of $5 \mathrm{kHz}$. In particular, the half-height line width is very similar in both cases. In the so-called weak collision regime, the contribution to $\delta v_{1 / 2}$ induced by the motional modulation of the chemical shift anisotropy, denoted as $1 /\left(\pi T_{2 \sigma}\right)$, is expected to be proportional to $v_{\mathrm{r}}^{-2}$ in the case of slow motions, i.e. when the characteristic correlation time $\tau$ of the probed motions is much higher than $v_{\mathrm{r}}^{-1} \cdot{ }^{44,49}$ The 
similar line shapes observed at $243 \mathrm{~K}$ for MAS spinning speeds of 5.0 and $2.5 \mathrm{kHz}$ indicate that the line broadening occurring around $243 \mathrm{~K}$ is not induced by a motional modulation of the PEO carbon chemical shift anisotropy. In contrast, the half-height line width of the PEO ${ }^{13} \mathrm{C}$ NMR peak displays a strong dependence on the ${ }^{1} \mathrm{H}$ decoupling field strength $v_{\text {dec. }}$. At $223 \mathrm{~K}, \delta v_{1 / 2}$ increases from $417 \mathrm{~Hz}$ to $1024 \mathrm{~Hz}$ as $v_{\text {dec }}$ is lowered from 52 to $19 \mathrm{kHz}$. At $373 \mathrm{~K}$, a similar line width is obtained, whatever the ${ }^{1} \mathrm{H}$ decoupling field strength. These experimental features confirm that the line broadening shown in Figure 8 can be assigned to the motional modulation of the $\mathrm{PEO}{ }^{1} \mathrm{H}-{ }^{13} \mathrm{C}$ dipolar couplings. Indeed, in the so-called weak collision regime, the contribution to $\delta v_{1 / 2}$ related to the motional modulation of the ${ }^{1} \mathrm{H}-$ ${ }^{13} \mathrm{C}$ dipolar couplings, denoted as $1 /\left(\pi T_{2 \mathrm{~m}}\right)$, is expected to display a strong dependence on the intensity of the ${ }^{1} \mathrm{H}$ decoupling field $\left(1 /\left(\pi T_{2 \mathrm{~m}}\right) \propto v_{\mathrm{dec}}{ }^{-2}\right)$ in the case of slow motions and should not vary with $v_{\mathrm{dec}}$ in the fast motion regime. Here, "slow" ("fast") means that the correlation time $\tau$ of the probed motions is higher (lower) than $v_{\mathrm{dec}}{ }^{-1} \cdot{ }^{44,48}$ From these results, one can conclude that at $243 \mathrm{~K}$, a significant part of the PEO monomer units undergoes reorientational motions occurring at a frequency of $52 \mathrm{kHz}$.

It is also of interest to compare the $\delta v_{1 / 2}(T)$ variation measured on the PEO/laponite(30/70) nanocomposite and amorphous chain segments of neat PEO. Higher temperature is required to lead the motional frequencies of the intercalated PEO monomer units to $52 \mathrm{kHz}$. Indeed, in the PEO/laponite intercalated phase, at $263 \mathrm{~K}$ for instance, $\delta v_{1 / 2}(T)$ is more than 5 times higher than its high-temperature limit value, which indicates that a non-negligible fraction of the confined PEO monomer units have not yet reached a motional frequency of $52 \mathrm{kHz}$. In contrast, at the same temperature, in the amorphous phase of the neat PEO matrix, $\delta v_{1 / 2}$ has nearly achieved its high-temperature plateau value, implying that the characteristic motional frequencies related to most of the amorphous PEO chain segments are above $52 \mathrm{kHz}$. Therefore, the measurements reported in Figure 6 show that in the PEO/laponite(30/70) nanocomposite, a large amount of PEO chain segments displays a significant slowing down of their segmental mobility, compared to the segmental dynamics in the amorphous phase of the bulk PEO matrix. 


\subsection{Proton NMR Line Shapes.}

The occurrence of segmental motions faster for some units of the PEO/laponite intercalated phase than in the amorphous phase of neat PEO is a question of interest. To address this question from an experimental point of view, ${ }^{1} \mathrm{H}$ MAS NMR spectra were recorded on the PEO/laponite(30/70) nanocomposite at a MAS spinning speed of $5 \mathrm{kHz}$ and for temperatures ranging from $293 \mathrm{~K}$ down to 217 K. Some representative spectra are reported in Figure 9. As expected, when the temperature decreases, the line shape of the peak related to the clay $\mathrm{OH}$ protons remains nearly unchanged. In contrast, the peak corresponding to the amorphous PEO chain protons broadens, with a half-height line width varying from $278 \mathrm{~Hz}$ at room temperature to $1032 \mathrm{~Hz}$ at $243 \mathrm{~K}$, and the area under this peak displays a faster decrease than the one related to the clay $\mathrm{OH}$ protons as the temperature is raised down. The PEO segmental motions are indeed slowed down as the glass transition is approached and the faster decrease in the PEO peak area indicates that a growing part of the chain segments gets frozen over the tens of microseconds time scale.

It is worth comparing these data with the ${ }^{1} \mathrm{H}$ MAS NMR spectra obtained on the neat PEO homopolymer, under the same experimental conditions. At room temperature, only the protons of the PEO monomer units involved in the amorphous phase contribute to the rather narrow peak at $3.5 \mathrm{ppm}$. The protons related to the PEO crystallites give rise to a spectral contribution that is very broad (a few tens of kilohertz), wider than the spectral window used for these experiments. The half-height line width for the narrow peak at $3.5 \mathrm{ppm}$ is $126 \mathrm{~Hz}$, i.e. narrower than the one measured in the nanocomposite $(236 \mathrm{~Hz})$. This comparison suggests that even though part of the segmental motions in the amorphous phase of bulk PEO is constrained and slowed down by the PEO crystallites, slower motions are detected, at the same temperature, on the fully amorphous PEO chains intercalated within the clay platelets. Such a result is somehow consistent with the slowing down of a significant part of the PEO chain segments evidenced by the ${ }^{13} \mathrm{C}$ NMR approach described in the previous section. It also gives a qualitative indication of the amplitude of the dynamical slowing down induced by the laponite discs: the corresponding constraints induce stronger effects on the dynamics of the amorphous PEO chain 


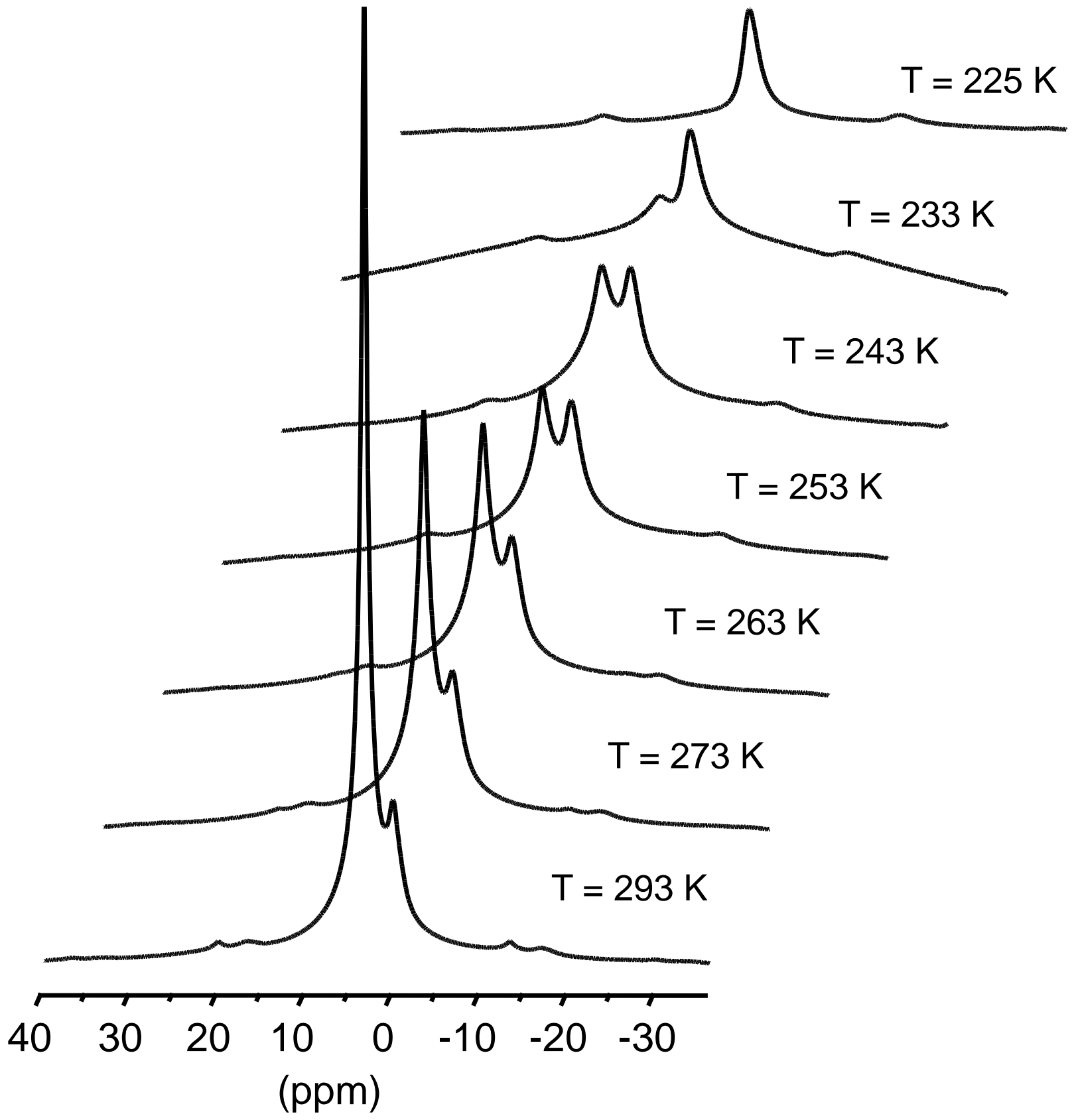

Figure 9. Representative ${ }^{1} \mathrm{H}$ MAS NMR spectra obtained on the PEO/laponite(30/70) nanocomposite for temperatures ranging from $293 \mathrm{~K}$ to $217 \mathrm{~K}$. The MAS spinning speed was set to $5 \mathrm{kHz}$.

From another point of view, in the PEO/laponite(30/70) nanocomposite, the $\mathrm{PEO}{ }^{1} \mathrm{H}$ NMR peak at $3.6 \mathrm{ppm}$ becomes so broad around $226 \mathrm{~K} \pm 1 \mathrm{~K}$ that below this temperature, it cannot be observed any longer as a narrow contribution in the considered spectral window. Comparatively, the ${ }^{1} \mathrm{H}$ NMR 
contribution related to the amorphous phase of the neat PEO homopolymer is not observed as a resolved peak below a lower temperature of $218 \mathrm{~K} \pm 1 \mathrm{~K}$. This feature shows that in the PEO/laponite intercalated phase, large-amplitude reorientational motions characterized by faster correlation times than the ones related to amorphous chain segments in the bulk PEO matrix are not detected. In other words, two possible schemes for the segmental dynamics of these confined PEO chains permit to interpret the ${ }^{1} \mathrm{H}$ MAS NMR data. A first possibility is to consider that no (or at least too few to be observed) PEO monomer unit displays segmental motions faster than the segmental dynamics of the neat PEO amorphous phase. The second scheme involves the occurrence of PEO segmental motions faster than the ones displayed in the amorphous phase of bulk PEO, potentially resulting from the chain confinement induced by the clay platelets: however, the motional amplitude of such reorientations becomes so restricted below $226 \mathrm{~K}$ that they do not give rise to a rather narrow contribution on the corresponding ${ }^{1} \mathrm{H}$ NMR line shape.

A complementary approach was used to get a better understanding of the PEO ${ }^{1} \mathrm{H}$ NMR line shape observed on the PEO/laponite(30/70) nanocomposite, at room temperature. The contribution to the 1D ${ }^{1} \mathrm{H}$ NMR spectrum resulting from the PEO chain segments in the close vicinity of the clay layers was extracted through 2D ${ }^{1} \mathrm{H}-{ }^{1} \mathrm{H}$ correlation experiments with spin-diffusion. This method was fruitfully used to probe the location and the dynamical behavior of PEO chain segments in PEO/hectorite ${ }^{30}$ as well as polystyrene-poly(ethylene oxide) (PS-PEO) diblock copolymers/hectorite ${ }^{33}$ nanocomposites.

The $2 \mathrm{D}{ }^{1} \mathrm{H}-{ }^{1} \mathrm{H}$ correlation spectrum obtained on the $\mathrm{PEO} /$ laponite $(30 / 70)$ intercalated phase with a mixing time $t_{\mathrm{m}}$ of $4 \mathrm{~ms}$ is depicted in Figure 10a. The cross-section along the indirect dimension, taken at the ${ }^{1} \mathrm{H}$ chemical shift of the laponite protons in the second dimension $(\delta=0.2 \mathrm{ppm})$, displays the spectral contribution of the PEO protons characterized by a ${ }^{1} \mathrm{H}$ magnetization that is equilibrated with the magnetization of the clay $\mathrm{OH}$ protons. In other words, this cross-section permits to obtain the ${ }^{1} \mathrm{H}$ NMR peak of the PEO protons located within the ${ }^{1} \mathrm{H}$ spin-diffusion length, corresponding to the mixing time $t_{\mathrm{m}}$, from the laponite layer surfaces. For $t_{\mathrm{m}}=4 \mathrm{~ms}$ for instance, a contribution at $3.6 \mathrm{ppm}$ is observed on the cross-section shown in Figure 10b. Such a ${ }^{1} \mathrm{H}$ NMR peak, which is not detected, as 
expected, when the mixing time is set to a few microseconds, may be assigned to the PEO chain segments in the close surrounding of the laponite layers (within 0.5-1.0 nm from the platelet surfaces). It is worth remarking that the half-height line width of this interfacial contribution, which amounts to about $475 \mathrm{~Hz}$, is broader than the one of the PEO ${ }^{1} \mathrm{H}$ NMR peak, measured on the $1 \mathrm{D}{ }^{1} \mathrm{H}$ NMR spectrum of the same sample (about $185 \mathrm{~Hz}$ ). The same conclusion holds when the comparison is carried out with the half-height line width measured on the PEO contribution observed on the crosssection along the indirect dimension, taken at the PEO proton chemical shift $(\delta=3.6 \mathrm{ppm})$ in the second dimension (Figure 10c). As the mixing time $t_{\mathrm{m}}$ is increased, the spectral contribution of PEO protons determined on both cross-sections (cross-sections along the indirect dimension, taken at 0.2 and $3.6 \mathrm{ppm}$ respectively in the direct dimension) tends to a common line width value. For $t_{\mathrm{m}}=289 \mathrm{~ms}$, the PEO ${ }^{1} \mathrm{H}$ NMR line shape is identical on both cross-sections, as a result of the ${ }^{1} \mathrm{H}$ spin-diffusion process that equilibrates the ${ }^{1} \mathrm{H}$ magnetization of all the $\mathrm{PEO}$ protons and the magnetization of the laponite $\mathrm{OH}$ protons.

The difference in the PEO ${ }^{1} \mathrm{H}$ NMR line shape, detected at mixing time values of a few milliseconds, suggests the occurrence of a mobility gradient among the PEO monomer units in the PEO/laponite(30/70) nanocomposite. In particular, a reduced segmental mobility is observed for the PEO chain segments located in the close vicinity of the laponite discs. Other PEO monomer units, displaying a higher segmental mobility on average, are also detected and also contribute to the global PEO ${ }^{1} \mathrm{H}$ NMR line shape recorded through the 1D MAS NMR experiments. Such chain segments should be located at higher distances from the surfaces of the clay platelets. 
(a)
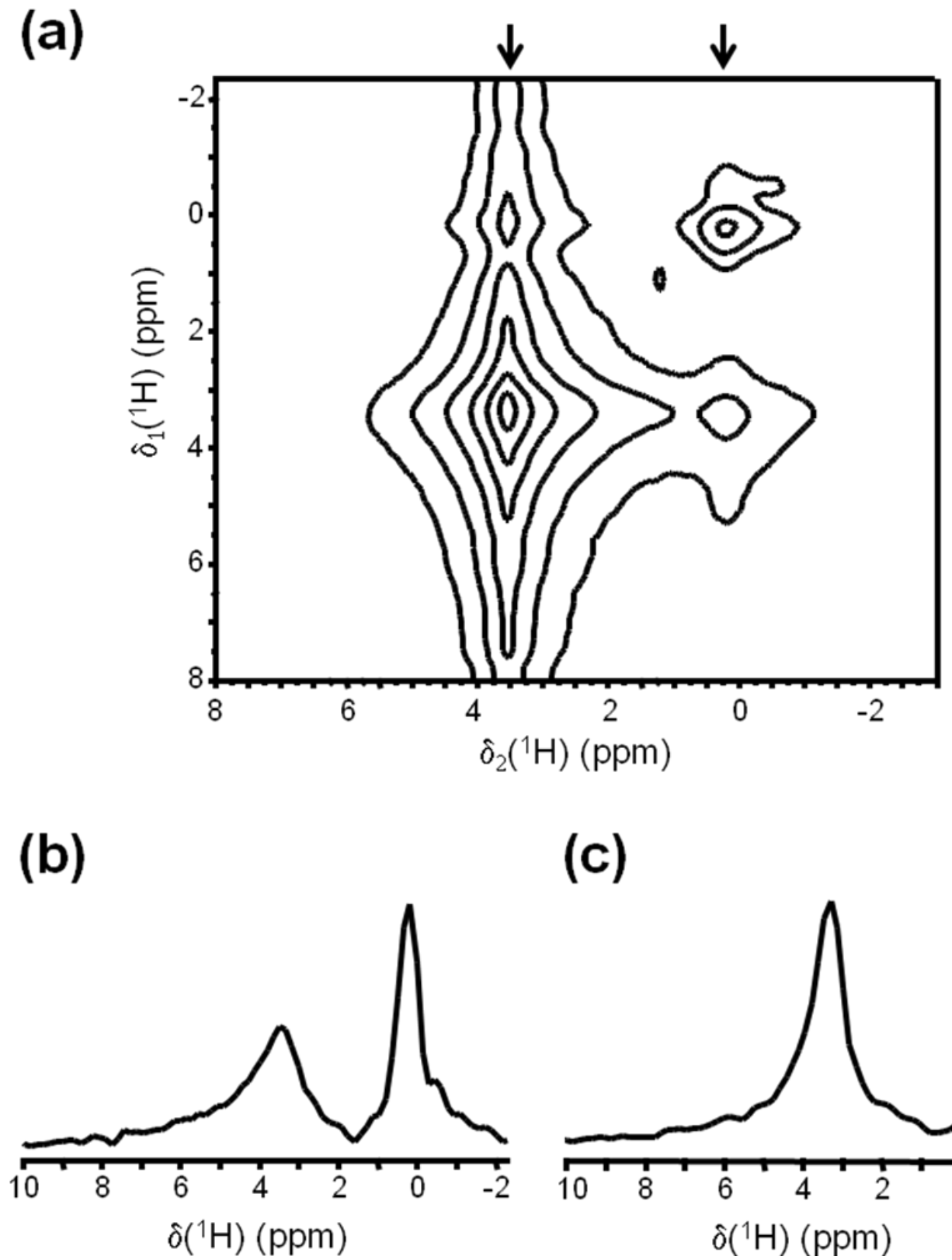

(c)

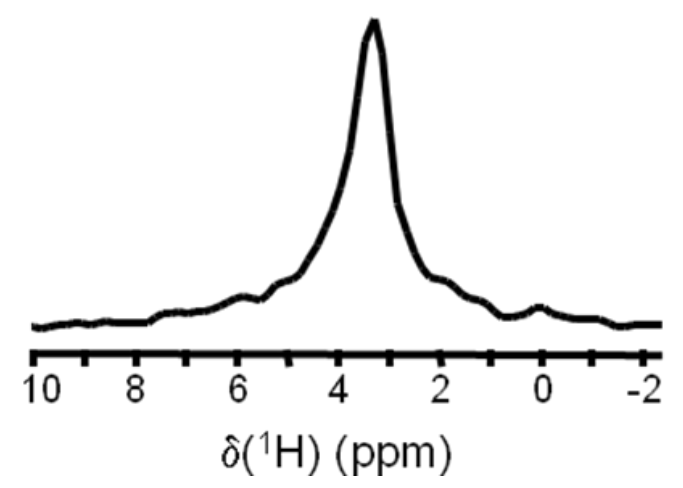

Figure 10. (a) $2 \mathrm{D}{ }^{1} \mathrm{H}-{ }^{1} \mathrm{H}$ correlation spectrum obtained on the $\mathrm{PEO} /$ laponite(30/70) nanocomposite, at room temperature, with a mixing time $t_{\mathrm{m}}$ of $4 \mathrm{~ms}$; (b) Cross-section along the indirect dimension, taken at $\delta=0.2 \mathrm{ppm}$ (laponite $\mathrm{OH}$ protons) in the direct dimension; (c) Cross-section along the indirect dimension, taken at $\delta=3.5 \mathrm{ppm}$ (PEO protons) in the direct dimension.

\section{Discussion.}

In the intercalated phases that can be found in polymer/clay nanocomposites characterized by usual clay contents ranging between 1 and $5 \mathrm{wt} \%$, polymer chains are submitted to a severe geometric 
confinement. In the present case, the thickness $e$ of the PEO films between the laponite layers is found to be close to $0.9 \mathrm{~nm}$, as deduced from small-angle X-ray scattering experiments. ${ }^{39}$ This value is very small compared to the undisturbed radius of gyration $R_{\mathrm{g}}$ of the PEO chains considered here, which can be roughly estimated to $26 \mathrm{~nm}$. Laponite consists in discoid platelets with an average diameter of about $25 \mathrm{~nm}$. Thus, a given PEO chain should be intercalated within different laponite layers and this feature should increase the $e / R_{\mathrm{g}}$ ratio. Anyway, whatever the exact value of this ratio in the PEO/laponite(30/70) intercalated phase, the PEO chains are constrained to move within a 1D-confined space. Numerous studies have been dedicated during the last ten years to the glass transition phenomena in polymer thin films. In particular, experiments carried out on suspended films showed a significant depression in the glass transition temperature, $T_{\mathrm{g}}$, as soon as the film thickness enters in the range of or gets lower than twice the undisturbed radius of gyration of the polymer chains ${ }^{50}$ One can expect such confinement effects to affect the PEO segmental dynamics in the PEO/laponite intercalated phase. At the same time, intercalation of PEO chains in the interlayer galleries formed by the clay discoids is thermodynamically driven by attractive interactions between both components, such as hydrogen bonds formed between PEO monomer units and the silanol groups at the surface of the laponite platelets, for instance. Such attractive interactions may induce a slowing down of the PEO segmental motions. As a result, one may expect the PEO segmental dynamics to be deeply modified in this intercalated phase, compared to the one in the free amorphous phase of bulk PEO. However, both geometric confinement and polymer/clay interactions should lead to antagonistic effects and the resulting PEO segmental dynamics will depend on the balance of these two effects.

The ${ }^{13} \mathrm{C} C P / M A S / D D$ and DP/MAS/DD NMR experiments carried out at room temperature on the PEO/laponite(30/70) nanocomposite demonstrated the occurrence of pronounced dynamical heterogeneities in the PEO segmental dynamics within the clay galleries. The temperature dependence of both ${ }^{13} \mathrm{C}$ and ${ }^{1} \mathrm{H}$ NMR spectra showed a pronounced motional slowing down displayed by a significant part of the PEO chain segments, as compared to the local dynamics of the amorphous phase of the neat PEO matrix. From another point of view, PEO monomer units characterized by largeamplitude reorientational motions faster than in the amorphous phase of bulk PEO were not observed. 
At this stage, it is of interest to compare the results obtained with the $\mathrm{PEO} /$ laponite intercalated phase to data reported on PEO-based nanocomposites involving fluorohectorite $25,26,31$ or synthetic montmorillonite. ${ }^{29}$ Such comparisons should be made with great care since, even though these studies are dedicated to intercalated phases, PEO crystallites were detected by DSC in some of them. ${ }^{29}$ The occurrence of crystallites, which arise from the preparation method (melt intercalation in reference 29 against exfoliation/adsorption in the present work), suggests that in such materials, all the PEO chains are not intercalated within the clay galleries. Therefore, the data related to the PEO segmental motions include a contribution from non-intercalated monomer units and in addition, the PEO crystallites, necessarily located outside the interlayer spacing, may affect the dynamics of chain portions anchored to them and intercalated within the clay galleries. Anyway, the general trend reported for the PEO segmental motions by Kwiatkowski et al. ${ }^{29}$ is, qualitatively, in agreement with the results reported on deuterated PEO/fluorohectorite by ${ }^{2} \mathrm{H}$ NMR. ${ }^{25,26,31}$ The second point that should be mentioned before going further into any comparison between the different sets of data is that the clays used to prepare the intercalated phases were not the same. It implies that the strength of the interactions between the clay layers and the PEO chains is not identical, since the cation exchange capacity (CEC) and the OH group concentration per area unit may differ from a clay to another. The CEC of the phyllosilicates considered in the different works under comparison are in the range 0.7-1.4 meq.g-1 ${ }^{-1}$ Similarly, though not identical, the values of the hydroxyl group concentration for these clays (or fluorine atoms for fluorohectorite) are of the same order of magnitude. Lastly, it is also important to note that the diameter of the laponite discs (about $25 \mathrm{~nm}$ ) is much smaller than the average lateral size of the phyllosilicate platelets considered in references 25,26, 29 and 31. In the PEO/laponite(30/70) intercalated phase, the lateral size of the clay layers is of the same order of magnitude than the undisturbed radius of gyration $R_{\mathrm{g}}$ of the amorphous PEO chains. This situation differs somehow from the previous investigations of the PEO segmental dynamics in PEO/clay intercalated phases, involving confining layers with large lateral sizes compared to the $R_{\mathrm{g}}$ value of the PEO chains considered. ${ }^{25,26,29,31}$ As a result, one may expect a weaker chain confinement constraint in the PEO/laponite(30/70) nanocomposite. For all these reasons and also due to 
the differences in the bulk organization of PEO chains in the nanocomposites compared, we will restrict our analysis to qualitative features.

In previous studies of $\mathrm{PEO} /$ phyllosilicate intercalated phases, fast motions, over the microsecond time scale, are detected at temperatures for which the motions of the monomer units are frozen in the amorphous phase of bulk PEO. ${ }^{25,26,29,31}$ At first glance, this result may seem in contradiction with the fact that the PEO ${ }^{1} \mathrm{H}$ NMR peak displays a significant broadening in the $\mathrm{PEO} /$ laponite intercalated phase at temperatures higher than in the amorphous phase of bulk PEO (Figure 9). However, the absence of a narrow contribution for the ${ }^{1} \mathrm{H}$ NMR peak at $3.6 \mathrm{ppm}$ does not necessarily mean that the correlation times of the PEO segmental motions are lower than the microsecond time scale: one cannot discard the occurrence of fast motions with a small reorientational amplitude, which would lead to a weak motional averaging of the ${ }^{1} \mathrm{H}-{ }^{1} \mathrm{H}$ dipolar couplings related to the $\mathrm{PEO}$ monomer units. Besides, small-amplitude motions of PEO chain segments would be consistent with the relatively high half-height line width of the "narrow" contribution (about $13 \mathrm{kHz}$ ) observed below $223 \mathrm{~K}$ in the PEO/synthetic montmorillonite nanocomposite studied in reference 29. Indeed, this value indicates a limited averaging effect of the static ${ }^{1} \mathrm{H}-{ }^{1} \mathrm{H}$ dipolar couplings, which amount to about $33 \mathrm{kHz}$ between both $\mathrm{CH}_{2}$ protons of a $\mathrm{PEO}$ monomer unit. In the PEO/laponite(30/70) nanocomposite under study, the broad spectral contribution arising from the intercalated PEO monomer units is somehow more difficult to observe on the ${ }^{1} \mathrm{H}$ MAS NMR spectra obtained below $233 \mathrm{~K}$, as can be seen in Figure 9, due to its overlap with the narrow contribution of the clay $\mathrm{OH}$ proton peak (half-height line width of $0.42 \mathrm{kHz}$ ). This situation differs from the one of reference 29 , where the fraction of protons related to the clay component was negligible. The comparison with data reported in reference 29 indicates that in the PEO/laponite(30/70) intercalated phase considered in this study, the PEO contribution to the ${ }^{1} \mathrm{H}$ MAS NMR spectrum is broader than the "narrow" line observed in the PEO/synthetic montmorillonite nanocomposite, below $223 \mathrm{~K}$. Despite these quantitative differences in the line width values, in both cases, the experimental data may be compatible with the occurrence of fast small-amplitude PEO reorientational motions within the clay layers. 
The most relevant feature of the segmental dynamics in this PEO/laponite intercalated phase stands in its significant heterogeneity and the motional slowing down displayed by a significant part of the chain segments. At this point, it is worth commenting the extent of the PEO chain intercalation between the laponite discs, in the $\mathrm{PEO} /$ laponite(30/70) nanocomposite. $2 \mathrm{D}{ }^{1} \mathrm{H}-{ }^{1} \mathrm{H}$ correlation experiments with spin-diffusion evidenced a mobility gradient occurring among the PEO monomer units. In particular, in addition to the chain segments in the close surrounding of the laponite disc surfaces, PEO monomer units displaying, comparatively, a higher degree of segmental mobility are detected as the distance from the clay layers increases. This feature may result from PEO chain segments that are not intercalated within the Van der Waals gaps. By the way, in the PEO/laponite(30/70) nanocomposite, the PEO film thickness is of about $0.9 \mathrm{~nm}$. Thus, assuming a unidirectional ${ }^{1} \mathrm{H}$ spin-diffusion process occurring along the normal to the laponite discs, the mixing time required to get a full equilibration between the magnetization of the clay protons and the magnetization of the intercalated PEO protons may be estimated to about $8 \mathrm{~ms}$. If all the PEO monomer units were confined between the laponite layers, similar PEO ${ }^{1} \mathrm{H}$ NMR line shapes should be observed on the cross-sections along the indirect dimension, taken at the chemical shift of the clay $\mathrm{OH}$ protons and at the chemical shift of the PEO protons in the second dimension, for $2 \mathrm{D}{ }^{1} \mathrm{H}-{ }^{1} \mathrm{H}$ correlation spectra obtained with mixing time values higher than $8 \mathrm{~ms}$. This is not the case experimentally, confirming that a part of the PEO chain segments is not confined between the laponite platelets. These non-intercalated units do not form PEO domains characterized by a typical size of a few nanometers or more, since no PEO crystallites were detected through the DSC and WAXS measurements carried out on this nanocomposite. They should rather be involved in limited sequences along the PEO chains, bridging two chain portions that intercalate the laponite galleries. In the present case, the PEO chain length is rather high while the typical laponite disc diameter is rather limited (about $25 \mathrm{~nm}$ ) and of the same order of magnitude as the undisturbed radius of gyration of the polymer chains. As a result, non-intercalated chain portions sticking out the galleries may represent a limited but non-negligible fraction of the PEO monomer units in the PEO/laponite(30/70) nanocomposite. Of course, they should contribute to the significant dynamical heterogeneities detected through the $1 \mathrm{D}{ }^{13} \mathrm{C}$ and ${ }^{1} \mathrm{H}$ NMR experiments reported in 
this study. However, the results of the $2 \mathrm{D}{ }^{1} \mathrm{H}-{ }^{1} \mathrm{H}$ correlation experiments suggest a comparatively higher level of segmental mobility for the non-intercalated PEO monomer units. In the following, the analysis of the data will be mainly focused on the chain segments displaying the slowest segmental motions, which should mostly correspond to units located close to the laponite layers.

Our experiments permitted to estimate the shift of the $T_{\alpha}$ temperature required to lead the frequency of the maximum of the PEO $\alpha$-relaxation peak to $52 \mathrm{kHz}$, in the $\mathrm{PEO} / \mathrm{laponite}(30 / 70)$ nanocomposite. An increase of at least $10 \mathrm{~K}-20 \mathrm{~K}$ was found. It should be noted that the ${ }^{13} \mathrm{C}$ NMR experiments used in this study are probing molecular motions at rather high frequencies (tens of kilohertz). As a result, a higher deviation in the $T_{\alpha}$ value would be obtained using NMR experiments or any relaxation techniques probing motions at a frequency of $1 \mathrm{~Hz}$ for instance. Another interesting feature of the PEO segmental dynamics in the PEO/laponite intercalated phase is the broadening of the distribution of the motional frequencies related to the PEO $\alpha$-relaxation process, in particular towards the low frequency values. Indeed, even at room temperature, i.e. more than $50 \mathrm{~K}$ above the temperature leading the characteristic frequency of the PEO segmental motions to $52 \mathrm{kHz}$, part of the monomer units still displays an efficient cross-polarization efficiency at short contact time values (20 $\mu$ s typically). The detailed analysis of the ${ }^{13} \mathrm{C}$ NMR line shape shows the occurrence of dynamical heterogeneities among the PEO chain segments in the PEO/laponite(30/70) nanocomposite. A distribution of motional averaged ${ }^{1} \mathrm{H}-{ }^{13} \mathrm{C}$ dipolar couplings was detected and interestingly, a correlation between the strength of these residual couplings and the ${ }^{13} \mathrm{C}$ chemical shift of the corresponding PEO carbons was evidenced: the lower the mobility of a PEO monomer unit, the lower the chemical shift of its carbons. A possible interpretation of this result would be to consider that the highest residual ${ }^{1} \mathrm{H}-{ }^{13} \mathrm{C}$ dipolar couplings are related to $\mathrm{PEO}$ monomer units forming hydrogen bonds with the clay $\mathrm{OH}$ groups. Such attractive interactions are indeed expected to decrease the mobility of the involved units. Another possible interaction that may account for the strongest values of the PEO ${ }^{1} \mathrm{H}-{ }^{13} \mathrm{C}$ dipolar couplings is the complexation of the ether oxygens by the $\mathrm{Na}^{+}$ions compensating the negative charge of the clay platelets. The first kind of interactions (hydrogen bonds) is expected to induce a downfield shift of the 
contribution related to the involved monomer units on the ${ }^{13} \mathrm{C} N \mathrm{NM}$ spectrum. In contrast, an upfield shift of the ${ }^{13} \mathrm{C}$ chemical shift should occur for PEO monomer units complexed by cations, as previously evidenced in several investigations of PEO-based polymer electrolytes. ${ }^{51}$ In the present case, PEO chain segments displaying the lower segmental mobility are characterized by upfield shifts of their spectral contribution to the PEO ${ }^{13} \mathrm{C}$ NMR line shape, compared to the remaining monomer units. This trend suggests that their reduced segmental mobility may be mostly assigned to complexation phenomena with the $\mathrm{Na}^{+}$cations. Molecular dynamics simulations of PEO oligomers $/ \mathrm{Na}^{+}$-montmorillonite intercalated phases indicate that the $\mathrm{Na}^{+}$counterions spend most of their time close to the clay layers and only a very limited fraction of these cations are detected in the middle part of the galleries. ${ }^{9,10}$ One may reasonably expect this result to remain valid in the case of $\mathrm{PEO} /$ laponite intercalated phases and such a preferential localization of the $\mathrm{Na}^{+}$cations at the clay surfaces should facilitate the interactions between the PEO oxygen atoms and the sodium counterions, at the expense of the hydrogen bonds with the clay $\mathrm{OH}$ groups and account for the continuous decrease of the $\mathrm{PEO}{ }^{13} \mathrm{C}$ chemical shift related to monomer units characterized by decreasing levels of mobility.

Another mechanism could be invoked to account for the distribution of the ${ }^{13} \mathrm{C}$ chemical shift among the PEO carbons of the PEO/laponite(30/70) nanocomposite. Indeed, the difference in the diamagnetic susceptibility between both components of the intercalated phase - PEO thin films on the one hand and inorganic clay platelets on the other hand - may induce NMR magnetic field distortions at their interfaces. Such distortions may be responsible for chemical shift variations, as already observed on other kinds of lamellar structures. ${ }^{52}$ The maximum amplitude of such variations may be estimated for this geometry from the bulk magnetic susceptibilities $\chi$ of both components of the lamellar structure. For PEO, $\chi$ PEO may be approximated from the value reported for molten PEO homopolymers in the high molecular weight limit: $\chi \mathrm{PEO} \approx-0.622 \times 10^{-6} .{ }^{53}$ The $\chi$ value for laponite may be estimated using data recently reported for a synthetic montmorillonite: $\chi_{\text {Laponite }} \approx-0.384 \times 10^{-6} .{ }^{54}$ Even though the chemical composition of laponite and montmorillonite are somehow different, both 2:1 phyllosilicates do not contain any paramagnetic species, which is an important feature for the validity of our approximation. 
As a result, taking into account the volume fraction of amorphous PEO in the PEO/laponite intercalated phase considered in the present work (about 0.52), the expected variation in the PEO ${ }^{13} \mathrm{C}$ chemical shift should be lower than about $0.12 \mathrm{ppm}$. This value is much smaller than the chemical shift variation observed experimentally on the PEO/laponite(30/70) nanocomposite. Therefore, though based on rough approximations, the previous estimation suggests that the dispersion of the ${ }^{13} \mathrm{C}$ chemical shift related to the different PEO carbons in the clay galleries is mainly induced by $\mathrm{PEO}$ oxygens $/ \mathrm{Na}^{+}$complexation phenomena.

The ${ }^{13} \mathrm{C}$ NMR results obtained in the present investigation of a $\mathrm{PEO} /$ laponite intercalated phase indicates that a non-negligible fraction of the PEO chain segments displays slow segmental motions over the microsecond time scale. The contribution of such segments to the PEO ${ }^{13} \mathrm{C}$ NMR peak is located at high field values, about $69.2 \mathrm{ppm}$ (see Figure 5). The other PEO monomer units give rise to lower field contribution, up to about $70.2 \mathrm{ppm}$ for the more mobile species, which should include the non-intercalated chain segments, as discussed above. Obviously, reorientational motions may lead a given chain segment to experience both kinds of extreme environments, over the microsecond time scale probed by the ${ }^{13} \mathrm{C}$ NMR experiments used here and the distribution of possible lifetimes in both environments may account for the continuous increase of the ${ }^{13} \mathrm{C}$ chemical shift with the contact time observed in Figure 5: the higher the average time spent by a PEO monomer unit to interact with $\mathrm{Na}^{+}$ counterions or with clay $\mathrm{OH}$ protons, the higher the resulting ${ }^{1} \mathrm{H}-{ }^{13} \mathrm{C}$ dipolar couplings and the lower the ${ }^{13} \mathrm{C}$ chemical shift value. Therefore, the "composite" structure of the PEO ${ }^{13} \mathrm{C}$ NMR peak observed at room temperature and the underlying ${ }^{13} \mathrm{C}$ chemical shift difference among the monomer units indicate that the lifetime in low (or high) segmental mobility regions is rather high. Indeed, though the situation is more complex, one may describe, in a rough approach, the dynamical behaviour of the intercalated PEO chain segments by a two-site exchange model. One site would correspond to a PEO monomer unit in strong interactions with the $\mathrm{Na}^{+}$counterions or with the clay $\mathrm{OH}$ groups while the other site would be related to a PEO monomer unit displaying a bulk-like behaviour. At room temperature, the ${ }^{13} \mathrm{C}$ chemical shift of the two limit situations differs by about $1.0 \mathrm{ppm}$, meaning that the lifetime of a monomer unit in these low (or high) segmental mobility domains is higher than about $13 \mathrm{~ms}$. In contrast, at $373 \mathrm{~K}$, the 
${ }^{13} \mathrm{C}$ chemical shift of the PEO peak is not dependent on the ${ }^{1} \mathrm{H} \rightarrow{ }^{13} \mathrm{C}$ contact time: temperature is high enough to lead to a fast exchange process.

Finally, we would like to discuss the amplitude of the overall motional slowing down of the PEO chain segments observed in the PEO/laponite intercalated phase. Taking into account the chemical composition of laponite, one may estimate the $\mathrm{PEO}$ oxygen $/ \mathrm{Na}^{+}$counterion ratio to be close to $10 / 1$ in this sample. Therefore, it is interesting to compare the segmental dynamics of the intercalated PEO chains to the one occurring in Na-salt-containing PEO-based electrolytes. In particular, Wintersgill et al. considered PEO chains complexed with two different sodium salts, $\mathrm{NaCF}_{3} \mathrm{SO}_{3}$ and $\mathrm{NaI}^{55}$ Interestingly, in these polyelectrolytes, the PEO oxygen $/ \mathrm{Na}^{+}$cation ratio was set to $9 / 1$, i.e. a similar value to the one estimated for the PEO/laponite(30/70) nanocomposite. For both sodium salts, the complexation phenomena prevent the PEO crystallization and a significant increase of the PEO glass transition, $T_{\mathrm{g}}$, was detected by DSC: $T_{\mathrm{g}}=251 \mathrm{~K}$ with $\mathrm{NaCF}_{3} \mathrm{SO}_{3}$ and $T_{\mathrm{g}}=259 \mathrm{~K}$ with NaI. Clearly, these values are significantly higher than the temperature $T_{\alpha}=243 \mathrm{~K}$ obtained for the PEO chains complexed by the $\mathrm{Na}^{+}$ cations of the laponite interlayer galleries, even though $T_{\alpha}$ is deduced from high-frequency ${ }^{13} \mathrm{C}$ NMR measurements (tens of kilohertz). The lower glass transition temperature detected in the PEO/laponite intercalated phase may be assigned to the difference between the interaction strength involved by the $\mathrm{Na}^{+}$cations and the negatively charged laponite discs on the one hand and the cation-anion interaction strength involved in $\mathrm{NaCF}_{3} \mathrm{SO}_{3}$ or $\mathrm{NaI}$ on the other hand. One may also consider that the expected increase in the glass transition temperature of the intercalated PEO chains, induced by the complexation of the PEO oxygens by the laponite $\mathrm{Na}^{+}$cations, is partially counterbalanced by the $T_{\mathrm{g}}$ depression that could result from the severe geometric confinement undergone by the PEO chains. Probing the segmental dynamics in a Na-salt-containing PEO-based electrolyte with a similar $\mathrm{Na}^{+}$-anion interaction strength as between the $\mathrm{Na}^{+}$cations and the laponite layers would be of interest to discuss the occurrence of such confinement effects. Another way to address this question from an experimental point of view would be to investigate the PEO segmental motions close to the laponite layers in a neat $\mathrm{PEO} /$ laponite exfoliated phase. In such a polymer/clay nanocomposite structure, the chain confinement 
effects should be far less pronounced while the PEO oxygen $/ \mathrm{Na}^{+}$counterion complexation phenomena should not be modified.

\section{Conclusions.}

The PEO segmental motions in a model PEO/laponite intercalated phase were probed, at the molecular length scale and over the tens of microseconds time scale, using ${ }^{13} \mathrm{C}$ and ${ }^{1} \mathrm{H}$ solid-state NMR experiments. Significant dynamical heterogeneities among the PEO monomer units were observed at room temperature, i.e. more than $50 \mathrm{~K}$ above the temperature leading the characteristic motional frequency of the PEO $\alpha$-relaxation process to $52 \mathrm{kHz}$. While no large-amplitude reorientational motions faster than the segmental motions of the amorphous phase of bulk PEO could be detected, a significant amount of PEO monomer units were found to display a strong motional slowing down, as compared to neat amorphous PEO. This decrease in the segmental mobility was mainly assigned to the complexation of PEO oxygens by the $\mathrm{Na}^{+}$counterions located in the laponite interlayer galleries. The sodium cations would play the role of physical cross-links for the PEO chains and domains formed by monomer units displaying a reduced segmental mobility were characterized by a typical lifetime of the order of $13 \mathrm{~ms}$ at room temperature.

All these features point out the important role played by the $\mathrm{Na}^{+}$counterions on the glass transition of the intercalated PEO chains. The confinement effects may exist but in this case, they are counterbalanced by the PEO oxygen $/ \mathrm{Na}^{+}$cation complexation phenomena. Therefore, on the basis of these results, one way to get a deeper insight into the chain confinement effects induced by the clay layers on the PEO segmental dynamics might be to compare the dynamical behavior of intercalated PEO chains with the segmental motions in a Na-salt-containing PEO-based electrolyte, characterized by a $\mathrm{Na}^{+}$-anion interaction strength similar to the $\mathrm{Na}^{+}$-laponite layer interaction strength. 


\section{ACKNOWLEDGMENTS.}

C. L. and F. L. gratefully acknowledge CNRS and French Minister of Science for financial support and thank Région Ile-de-France for its participation in the purchase of the solid-state NMR spectrometer. 


\section{SUPPORTING INFORMATION PARAGRAPH.}

WAXS diffractograms obtained on PEO/laponite(30/70) and PEO/laponite(50/50) nanocomposites, neat laponite and bulk PEO are provided as well as the corresponding WAXS experimental details. This material is available free of charge via the Internet at http://pubs.acs.org. 


\section{REFERENCES.}

(1) Krishnamoorti, R.; Vaia, R. A. In Polymer Nanocomposites: Synthesis, Characterization, and Modeling; ACS Symposium Series; American Chemical Society: Washington, DC, 2002.

(2) Schmidt, G.; Malwitz, M. M. Curr. Opin. Colloid Interface Sci. 2003, 8, 103-108.

(3) Okada, A.; Usuki, A. Macromol. Mater. Eng. 2006, 291, 1449-1476.

(4) Powell, C. E.; Beall, G. W. Curr. Opin. Solid State Mater. Sci. 2006, 10, 73-80.

(5) Zeng, Q. H.; Yu, A. B.; Lu, G. Q. Prog. Polym. Sci. 2008, 33, 191-269.

(6) Manias, E.; Kuppa, V.; Yang, D.-K.; Zax, D. B. Colloids Surf. A-Physicochem. Eng. Asp. 2001, $187-188,509-521$.

(7) Kuppa, V.; Manias, E. J. Chem. Phys. 2003, 118, 3421-3429.

(8) Kuppa, V.; Menakanit, S.; Krishnamoorti, R.; Manias, E. J. Polym. Sci., Part B: Polym. Phys. 2003, 41, 3285-3298.

(9) Boulet, P.; Coveney, P. V.; Stackhouse, S. Chem. Phys. Lett. 2004, 389, 261-267.

(10) Mazo, M. A.; Manevitch, L. I.; Gusarova, E. B.; Shamaev, M. Y.; Berlin, A. A.; Balabaev, N. K.; Rutledge, G. C. J. Phys. Chem. B 2008, 112, 3597-3604.

(11) Alexandre, M.; Dubois, P. Mater. Sci. Eng.: R, Rep. 2000, 28, 1-63.

(12) Zax, D. B.; Yang, D.-K.; Santos, R. A.; Hegemann, H.; Giannelis, E. P.; Manias, E. J. Chem. Phys. 2000, 112, 2945-2951.

(13) Anastasiadis, S. H.; Karatasos, K.; Vlachos, G.; Manias, E.; Giannelis, E. P. Phys. Rev. Lett. 2000, $84,915-918$.

(14) Schwartz, G. A.; Bergman, R.; Swenson, J. J. Chem. Phys. 2004, 120, 5736-5744. 
(15) Wang, Z. M.; Nakajima, H.; Manias, E.; Chung, T. C. Macromolecules 2003, 36, 8919-8922.

(16) Chu, C.-C.; Chiang, M.-L.; Tsai, C.-M.; Lin, J.-J. Macromolecules 2005, 38, 6240-6243.

(17) Böhning, M.; Goering, H.; Fritz, A.; Brzezinka, K.-W.; Turky, G.; Schönhals, A.; Schartel, B. Macromolecules 2005, 38, 2764-2774.

(18) Mijović, J.; Lee, H. K.; Kenny, J.; Mays, J. Macromolecules 2006, 39, 2172-2182.

(19) Elmahdy, M. M.; Chrissopoulou, K.; Afratis, A.; Floudas, G.; Anastasiadis, S. H. Macromolecules 2006, 39, 5170-5173.

(20) VanderHart, D. L.; Asano, A.; Gilman, J. W. Chem. Mater. 2001, 13, 3781-3795.

(21) VanderHart, D. L.; Asano, A.; Gilman, J. W. Chem. Mater. 2001, 13, 3796-3809.

(22) Bourbigot, S.; VanderHart, D. L.; Gilman, J. W.; Awad, W. H.; Davis, R. D.; Morgan, A. B.; Wilkie, C. A. J. Polym. Sci., Part B: Polym. Phys. 2003, 41, 3188-3213.

(23) Aranda, P.; Ruiz-Hitzky, E. Chem. Mater. 1992, 4, 1395-1403.

(24) Harris, D. J.; Bonagamba, T. J.; Schmidt-Rohr, K. Macromolecules 1999, 32, 6718-6724.

(25) Wong, S.; Vasudevan, S.; Vaia, R. A.; Giannelis, E. P.; Zax, D. J. Am. Chem. Soc. 1995, 117, 7568-7569.

(26) Wong, S.; Vasudevan, S.; Vaia, R. A.; Giannelis, E. P.; Zax, D. Solid State Ionics 1996, 86, 547557.

(27) Wong, S.; Zax, D. Electrochim. Acta 1997, 42, 3513-3518.

(28) Reinholdt, M. X.; Kirkpatrick, R. J.; Pinnavaia, T. J. J. Phys. Chem. B 2005, 109, 16296-16303.

(29) Kwiatkowski, J.; Whittaker, A. K. J. Polym. Sci., Part B: Polym. Phys. 2001, 39, 1678-1685. 
(30) Hou, S.-S.; Beyer, F. L.; Schmidt-Rohr, K. Solid State Nucl. Magn. Reson. 2002, 22, 110-127.

(31) Yang, D.-K.; Zax, D. B. Solid State Nucl. Magn. Reson. 2006, 29, 153-162.

(32) Miwa, Y.; Drews, A. R.; Schlick, S. Macromolecules 2008, 41, 4701-4708.

(33) Hou, S.-S.; Bonagamba, T. J.; Beyer, F. L.; Madison, P. H.; Schmidt-Rohr, K. Macromolecules 2003, 36, 2769-2776.

(34) Hou, S.-S.; Schmidt-Rohr, K. Chem. Mater. 2003, 15, 1938-1940.

(35) McKenna, G. B. Eur. Phys. J. Special Topics 2007, 141, 291-301.

(36) Merabia, S.; Sotta, P.; Long, D. Eur. Phys. J. E. 2004, 15, 189-210.

(37) Herminghaus, S.; Jacobs, K.; Seemann, R. Eur. Phys. J. E. 2001, 5, 531-538.

(38) Gournis, D.; Floudas, G. Chem. Mater. 2004, 16, 1686-1692.

(39) Soulestin, J. Ph.D. Thesis, University of Sciences and Technologies, Lille, France, 2004.

(40) Bielecki, A.; Burum, D. P. J. Magn. Reson. 1995, A116, 215-220.

(41) Wunderlich, B. Thermal Analysis; Academic Press: Boston, 1990.

(42) Schönherr, H.; Frank, C. W. Macromolecules 2003, 36, 1199-1208.

(43) Marentette, J. M.; Brown, G. R. Polymer 1998, 39, 1405-1414.

(44) VanderHart, D. L.; Earl, W. L.; Garroway, A. N. J. Magn. Reson. 1981, 44, 361-401.

(45) Dechter, J. J. J. Polym. Sci., Polym. Lett. Ed. 1985, 23, 261-266.

(46) Johansson, A.; Tegenfeldt, J. Macromolecules 1992, 25, 4712-4715.

(47) Spěváček, J.; Brus, J.; Dybal, J. Solid State Ionics 2005, 176, 163-167. 
(48) Rothwell, W. P.; Waugh, J. S. J. Chem. Phys. 1981, 74, 2721-2732.

(49) Suwelack, D.; Rothwell, W. P. J. Chem. Phys. 1980, 73, 2559-2569.

(50) Dalnoki-Veress, K.; Forrest, J.A.; Murray, C.; Gigault, C.; Dutcher, J.R. Phys. Rev. E 2001, 63, 031801.

(51) Spindler, R.; Shriver, D. F. J. Am. Chem. Soc. 1988, 110, 3036-3043.

(52) Sotta, P.; Valić, S.; Deloche, B.; Maring, D.; Spiess, H. W. Acta Polym. 1999, 50, 205-213.

(53) Privalko, V. P.; Sobolev, V. B.; Rekhteta, N. A.; Sichko, V. N. J. Macromol. Sci., Part B: Phys. 1998, $37,765-771$.

(54) Levin, E. M.; Hou, S.-S.; Bud'ko, S. L.; Schmidt-Rohr, K. J. Appl. Phys. 2004, 96, 5085-5092.

(55) Wintersgill, M. C.; Fontanella, J. J.; Pak, Y. S.; Greenbaum, S. G.; Al-Mudaris, A.; Chadwick, A. V. Polymer 1989, 30, 1123-1126. 
For Table of Contents use only:

Title: Segmental Dynamics of Poly(ethylene oxide) Chains in a Model Polymer/Clay Intercalated Phase: Solid-State NMR Investigation.

Authors: $\quad$ Lorthioir, C.; Lauprêtre, F.; Soulestin, J.; Lefebvre, J.-M.

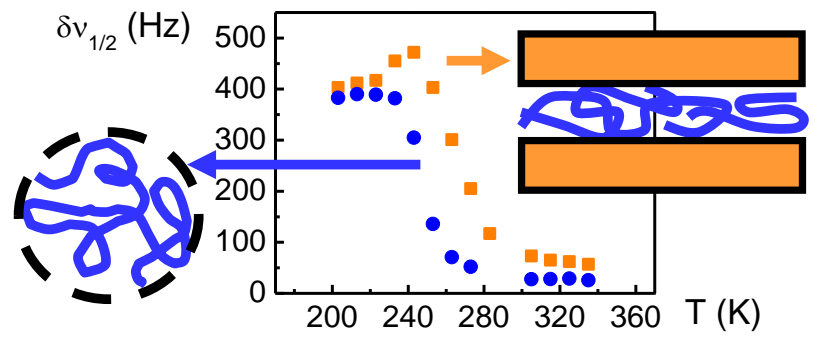

